\title{
Phosphorylation at Ser 727 Increases STAT3 Interaction with PKC $\varepsilon$ Regulating Neuron-Glia Crosstalk via IL-6-Mediated Hyperalgesia In Vivo and In Vitro
}

\author{
Xiongjuan Li $\mathbb{D}^{1}{ }^{1}$ Biqiang Zhou, ${ }^{2}$ Han Yang, ${ }^{1}$ Xinping Yang, ${ }^{1}$ Zhao Zhao, ${ }^{1}$ Zhenglong Pan, ${ }^{1}$ \\ Xinran Liao, ${ }^{1}$ Wenling Jian, ${ }^{1}$ Yuqiang Liu, ${ }^{1}$ Han Lu, ${ }^{3}$ Qingsheng Xue, ${ }^{3}$ Yan Luo, ${ }^{3}$ Buwei Yu, \\ Huansen Huang, ${ }^{4}$ Daqing Ma $\mathbb{D}^{5},{ }^{5}$ and Zhiheng Liu ${ }^{1}{ }^{1}$ \\ ${ }^{1}$ Department of Anesthesiology, Shenzhen Second People's Hospital, The First Affiliated Hospital of Shenzhen University, \\ Health Science Center, Shenzhen 518035, China \\ ${ }^{2}$ Department of Geriatric \& Spinal Pain Multi-Department Treatment, Shenzhen Second People's Hospital, The First Affiliated \\ Hospital of Shenzhen University, Health Science Center, Shenzhen 518035, China \\ ${ }^{3}$ Department of Anesthesiology, Ruijin Hospital Affiliated to Shanghai Jiaotong University, Shanghai 200025, China \\ ${ }^{4}$ Department of Anesthesiology, Second Affiliated Hospital of Guangzhou Medical University, No. 250 Changgangxi Road, \\ Guangzhou 510260, China \\ ${ }^{5}$ Division of Anaesthetics, Pain Medicine and Intensive Care, Department of Surgery and Cancer, Faculty of Medicine, \\ Imperial College London, Chelsea \& Westminster Hospital, London, UK
}

Correspondence should be addressed to Xiongjuan Li; li.xiongjuan@hotmail.com and Zhiheng Liu; zhiheng_liu_tongji@163.com

Received 15 October 2021; Revised 9 December 2021; Accepted 28 December 2021; Published 28 January 2022

Academic Editor: Joilson O. Martins

Copyright (C) 2022 Xiongjuan Li et al. This is an open access article distributed under the Creative Commons Attribution License, which permits unrestricted use, distribution, and reproduction in any medium, provided the original work is properly cited.

\begin{abstract}
Background and Aim. Interleukin-6 (IL-6) modulates neurons-glia crosstalk and subsequently triggers hyperalgesia. This study is aimed at investigating whether the interaction between protein kinase $\mathrm{C}$ epsilon $(\mathrm{PKC} \varepsilon)$ and signal transducer and activator of transcription 3 (STAT3) mediated IL-6-induced hyperalgesia and neurocyte activation. Methods. A rat hyperalgesia model was induced using an intraplantar injection of Freund's complete adjuvant (FCA) or an intrathecal injection of IL-6. Mechanical allodynia was evaluated using von Frey filament tests after intrathecal injections of T-5224 (c-Fos/AP-1 inhibitor), minocycline (Mino, a specific microglia inhibitor), L-2-aminoadipic acid (LAA, an astroglial toxin), PKCe inhibitor peptide, APTSTAT3-9R (STAT3 inhibitor), or anti-IL-6 antibody. The c-Fos, GFAP, Iba-1, PKCe, STAT3, pSTAT3 ${ }^{\text {Tyr705 }}$ and pSTAT3 ${ }^{\text {Ser727, and IL-6 }}$ expression at the spinal cord level was assessed by Western blot analysis. The interactive effects of PKCE and STAT3 were determined using immunofluorescence staining and immunoprecipitation in vivo and in vitro. Interleukin-6 promoter activity was examined using luciferase assays. Results. T-5224, Mino, and LAA attenuated FCA- or IL-6-mediated inflammatory pain, with a decrease in C-Fos, GFAP, Iba-1, PKCe, and IL-6 expression. PKCe inhibitor peptide and APTSTAT3-9R reversed FCAinduced nociceptive behavior, while decreasing pSTAT3 ${ }^{\text {Ser727 }}$, IL-6, c-Fos, GFAP, and Iba-1 expression and PKC $\varepsilon$ and STAT3 coexpression. Interleukin-6 promoter activity increased in the presence of PKC $\varepsilon$ and STAT3. The interaction with PKCe increased on phosphorylating STAT3 at Ser727 but not at Tyr705. Conclusion. STAT3 phosphorylation at Ser 727 and the interaction with $\mathrm{PKC \varepsilon}$ contribute to hyperalgesia via the IL-6-mediated signaling pathway, thus regulating neuron-glia crosstalk during inflammatory pain.
\end{abstract}

\section{Introduction}

Inflammatory mediators play important roles in pain development by interfering with nociceptive cellular signal trans- duction and transmission. The proinflammatory cytokine interleukin-6 (IL-6) is secreted by astrocytes and microglia in the central nervous system $[1,2]$. It might play an important role in the development and maintenance of 
hyperalgesia in various pain models [3]. The upregulation of IL-6 in the spinal cord causes mechanical hyperalgesia in rats and is associated with the nociceptive sensory process [4-6]. The dysregulation of IL-6 results in the production and release of several inflammatory mediators that may activate neurocytes and trigger neuropathic pain [3, 7]. The blockade of IL-6 signaling leads to substantial clinical improvement in inflammatory arthritis [8].

Protein kinase $\mathrm{C}(\mathrm{PKC})$ is an important family of intracellular signaling enzymes involved in central sensitization and pain transmission [9]. The PKC epsilon (PKCe) isoform is associated with the initiation of hyperalgesia by regulating nociceptor excitability $[10,11]$. Signal transducer and activator of transcription 3 (STAT3) modulates gene expression involved in promoting inflammatory pain. Notably, PKC $\varepsilon$ interacts with STAT3 [12], which targets and activates the IL-6 gene to increase IL-6 production [13, 14]. However, whether the interaction between PKC $\varepsilon$ and STAT3 affects IL-6-mediated neuron-glia activation and hyperalgesia remains unknown.

In this study, we sought to explore the interaction between $\mathrm{PKC}$, STAT3, and IL-6 during inflammationinduced hyperalgesia. First, we investigated whether PKC $\varepsilon$, STAT3, and IL-6 directly participated in neurocyte (including neurons, astrocytes, and microglia) activation during inflammatory pain in rats. Then, we aimed to determine the roles of PKCe and STAT3 in IL-6-induced hyperalgesia and neuron-glia crosstalk $[15,16]$ in vitro. Finally, we examined the interactions between PKCe and STAT3 as well as their effects on IL-6 promoter activity in vivo and in vitro.

\section{Materials and Methods}

2.1. Animals. A local experimental animal committee approved the experimental protocol, which was implemented according to the guidelines of the Institutional Animal Care and Use Committee (number 2019-004). Adult (6- to 8-week-old) male Sprague-Dawley rats weighing 200$220 \mathrm{~g}(n=130)$ were acclimated for 1 week under a $12 \mathrm{~h}$ light/dark cycle at $22^{\circ} \mathrm{C} \pm 2^{\circ} \mathrm{C}$ and $55 \% \pm 5 \%$ relative humidity and received food and water ad libitum.

2.2. Reagents and Administration. Reagents and antibodies were obtained from the following suppliers: c-Fos/AP-1 inhibitor T-5224, PKCe inhibitor peptide, and STAT3 inhibitor APTSTAT3-9R (Apexbio Technology LLC., TX, USA); specific microglia inhibitor minocycline hydrochloride (Mino) and astroglial toxin L-2-aminoadipic acid (LAA; Sigma-Aldrich Corp., MO, USA); and rat IL-6 and anti-IL6 antibodies (PeproTech Inc., NJ, USA and Abcam, Cambridge, UK, respectively). Anti-IL-6 and Mino were diluted with phosphate-buffered saline (PBS) and saline, respectively; the other agents were dissolved in 1\% dimethyl sulfoxide (DMSO). The aforementioned chemicals $(50 \mu \mathrm{L})$ were injected intrathecally via the L5-6 lumbar interspace identified by the tail flick reflex [17] under $1 \%-3 \%$ isoflurane (Baxter, IL, USA) anesthesia delivered at an oxygen flow rate of $1 \mathrm{~L} / \mathrm{min}$.
2.3. Inflammatory Pain and IL-6-Induced Hyperalgesia Model. Freund's complete adjuvant (FCA; Sigma-Aldrich Corp.) consisting of heat-killed Mycobacterium tuberculosis $(1 \mathrm{mg} / \mathrm{mL})$ in paraffin oil $(150 \mu \mathrm{L})$ was injected into the plantar area of the right hind paws of the rats under $1 \%-3 \%$ isoflurane anesthesia delivered with oxygen at a flow rate of $1 \mathrm{~L} / \mathrm{min}$. The left hind paw was not injected. Physical signs (e.g., redness and swelling) and pain behavior were monitored for $24 \mathrm{~h}$ after FCA injection. A model of hyperalgesia was established using naïve rats given an intrathecal injection of IL-6 $(20 \mathrm{ng} / 50 \mu \mathrm{L})$ through the L5-L6 lumbar interspace identified by the tail-flick reflex $10 \mathrm{~min}$ before drug administration under isoflurane anesthesia.

2.4. Experiments In Vivo. Figure 1 shows the experimental protocol in vivo.

2.4.1. Experiment 1 . The rats were randomly assigned to the following groups ( $n=6 /$ group): untreated (control naïve rats), FCA, FCA + T-5224 $500 \mu \mathrm{g} / 50 \mu \mathrm{L}$ (T-5224), FCA + Mino $100 \mu \mathrm{g} / 50 \mu \mathrm{L} \quad$ (Mino), FCA + LAA $1 \mathrm{mg} / 50 \mu \mathrm{L}$ (LAA), and PBS $50 \mu \mathrm{L}$ (vehicle).

2.4.2. Experiment 2. We investigated the roles of $\mathrm{PKC} \varepsilon$, STAT3, and IL-6 in the inflammatory process by randomizing rats to the following groups ( $n=6 /$ group): untreated (control naïve rats), FCA, FCA + PKCe inhibitor peptide $100 \mu \mathrm{g} / 50 \mu \mathrm{L} \quad$ (PKCe inhibitor), FCA + APTSTAT3-9R $20 \mu \mathrm{g} / 50 \mu \mathrm{L}$ (APTSTAT3-9R), FCA + anti-IL-6 antibody $100 \mathrm{ng} / 50 \mu \mathrm{L}$ (anti-IL-6), and 1\% DMSO $50 \mu \mathrm{L}$ (vehicle).

2.4.3. Experiment 3. We evaluated the effects of neuron-glial activity inhibitors on IL-6-induced hyperalgesia by randomizing rats to the following groups $(n=6 /$ group): untreated (control naïve rats), IL-6, IL-6 + T-5224 $500 \mu \mathrm{g} / 50 \mu \mathrm{L}$ (T5224), IL-6 + Mino $100 \mu \mathrm{g} / 50 \mu \mathrm{L}$ (Mino), IL-6 + LAA $1 \mathrm{mg} /$ $50 \mu \mathrm{L}$ (LAA), and $1 \%$ DMSO $50 \mu \mathrm{L}$ (vehicle). All inhibitors were injected intrathecally $10 \mathrm{~min}$ before IL-6 $(20 \mathrm{ng} / 50 \mu \mathrm{L})$.

2.4.4. Experiment 4. We assessed the effects of PKCe and STAT3 on IL-6-induced hyperalgesia by randomizing rats to the following groups ( $n=6 /$ group): untreated (control naïve rats), IL-6, IL-6 + PKC $\varepsilon$ inhibitor $100 \mu \mathrm{g} / 50 \mu \mathrm{L}$, IL-6 + APTSTAT3-9R $20 \mu \mathrm{g} / 50 \mu \mathrm{L}, \quad$ IL-6 + anti-IL-6 antibody $100 \mathrm{ng} / 50 \mu \mathrm{L}$, and PBS $50 \mu \mathrm{L}$ (vehicle). All drugs were injected intrathecally $10 \mathrm{~min}$ before IL-6 $(20 \mathrm{ng} / 50 \mu \mathrm{L})$.

The paw withdrawal mechanical threshold (PWMT) was measured daily after the intraplantar injection of FCA (Figure 1). All agents described earlier were injected intrathecally on days 4 and 6 after the intraplantar injection of FCA. The spinal cords were harvested on day 7. In the IL6-induced hyperalgesia model, the pain thresholds after chemical administration were assessed as the PWMT up to 120 min after IL-6 administration.

2.5. Von Frey Filament Tests. We measured PWMT using von Frey filament tests (Stoelting Co., IL, USA) using the up-and-down method [18]. The rats were habituated to a wire mesh platform for at least $1 \mathrm{~h} / \mathrm{d}$ for 3 days before starting experiments. All groups ( $n=6$ each) were tested daily 


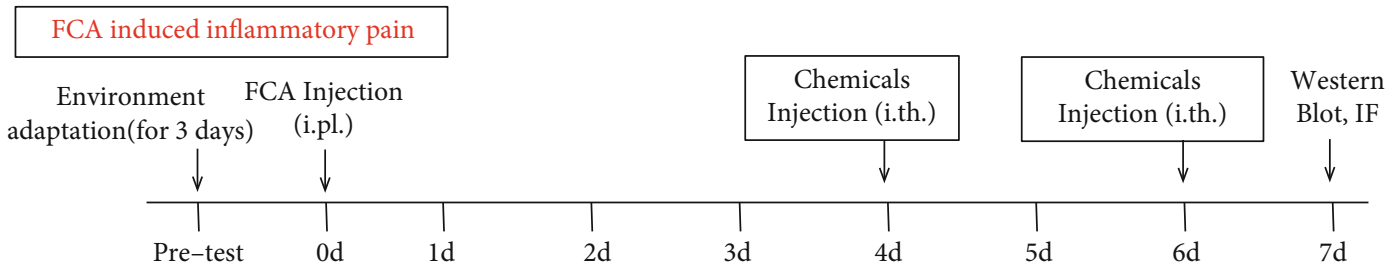

0th-7th day, daily paw withdraw mechanical thresholds test (before drug injection)

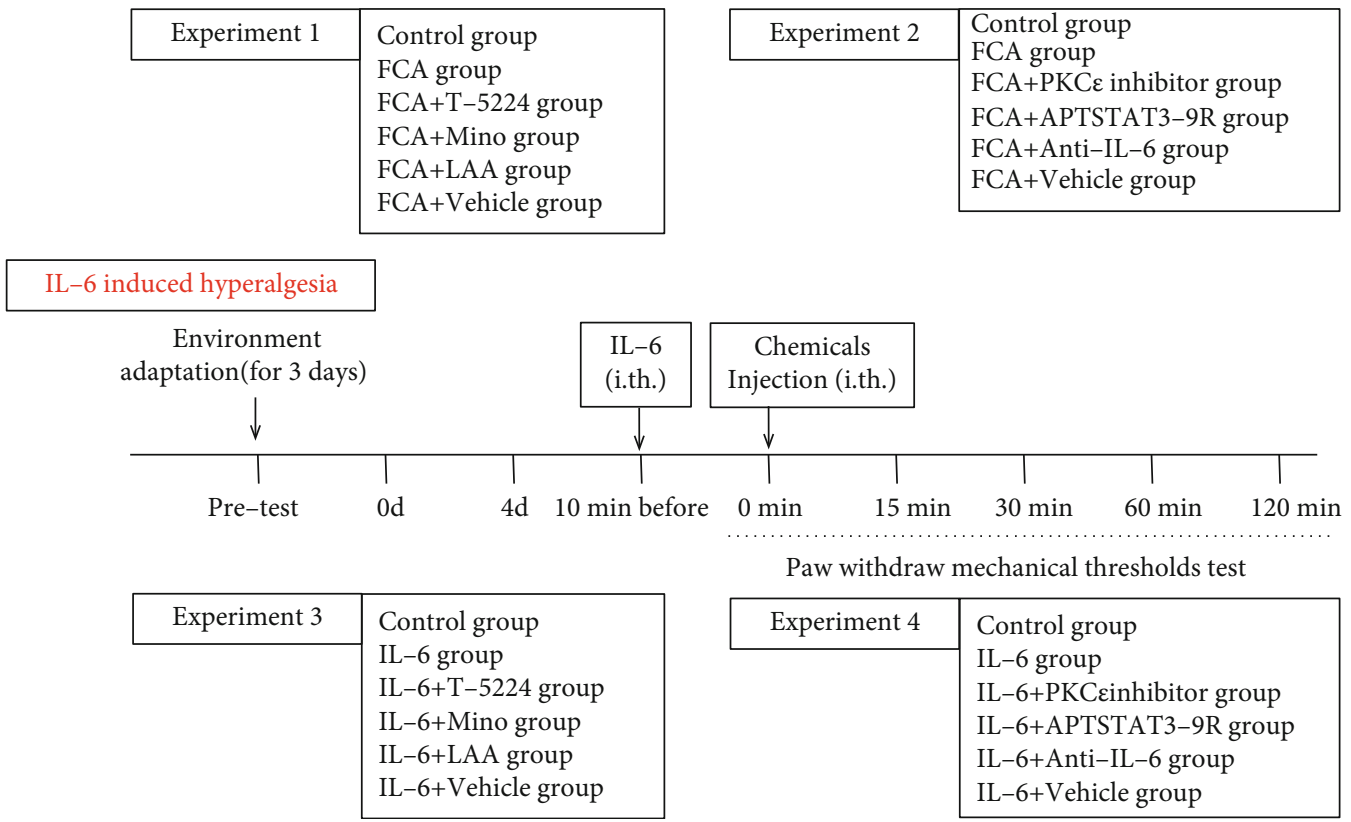

FIgURE 1: Schema of the experimental protocol. FCA: Freund complete adjuvant; IF: immunofluorescence; IL-6: interleukin-6; i.pl.: intraplantar; i.th.: intrathecal; LAA: L-2-aminoadipic acid; Mino: minocycline; PKCe: protein kinase C epsilon.

before drug application to determine baseline levels. Briefly, the positive and negative data were tabulated as follows: $X$ $=$ withdrawal and $0=$ nowithdrawal. The $50 \%$ response threshold was interpolated using the following formula: 50 $\% g$ threshold $=\left(10^{(x f+k \delta)}\right) / 10,000$, where $x f$ is the last value (in log units) of the von Frey filament test, $k$ is the tabular value for positive/negative responses, and $\delta$ is the mean difference (in log units) between stimuli [18]. The PWMT was defined as the means of six animals before and after chemical injections. Areas under receiver operator characteristic curves (AUC) were calculated to determine the effects of the injected chemicals.

2.6. Western Blot Analysis. The rats were euthanized using isoflurane anesthesia after the aforementioned tests. The lumbar segments (L3-L5) of whole spinal cords $(n=6$ /group) were homogenized and centrifuged at 16,000 g and $4^{\circ} \mathrm{C}$ for $15 \mathrm{~min}$. Equal amounts of protein $(50 \mu \mathrm{g})$ in supernatants were denatured, resolved by sodium dodecyl-sulfate polyacrylamide gel electrophoresis (SDS-PAGE, 5\% stacking gel, and $10 \%-12 \%$ separating gel), and then electrotransferred onto polyvinylidene difluoride (PVDF) membranes (Millipore, Massachusetts, USA). Nonspecific protein binding on the membranes was blocked with $5 \%$ nonfat milk in tri-buffered saline and Tween 20 (TBST) for $2 \mathrm{~h}$ at room temperature and then incubated with the primary antibodies: rabbit anti-c-Fos, anti-Iba-1, anti-PKCe, antiSTAT3 (1: 1000; Affinity Biosciences, OH, USA), anti-IL-6 ( $1: 1000$; Abcam, MA, USA), anti-GFAP, and anti-GAPDH (1:1000; Cell Signaling Technology, MA, USA). The blots were washed with TBST and then probed with secondary HRP goat anti-rabbit IgG $(1: 10,000)$ in $5 \%$ nonfat milk in TBST for $1 \mathrm{~h}$ at room temperature. The proteins of interest on the blots were visualized using an ECL reagent (Affinity Biosciences) and photographed using an X-ray film. The protein band intensity was quantified using the ImageJ software (National Institutes of Health, MD, USA).

2.7. Immunofluorescence Staining. After transcardial perfusion 7 days after FCA administration with $4 \%$ paraformaldehyde, the spinal cords were removed from the rats, postfixed, and dehydrated. Transverse frozen sections $(10 \mu \mathrm{m})$ prepared from OCT-embedded tissues were incubated overnight with rabbit polyclonal anti-PKCe (Abcam) and mouse monoclonal anti-STAT3 (Cell Signaling Technology). The proteins in the tissues were visualized using a DMIL LED scanning microscope (Leica Microsystems GmbH, Wetzlar, Germany). Primary or secondary antibodies were omitted to ensure staining specificity. The data from three to four sections per rat ( $n=6$ /group) were analyzed. 
2.8. Immunoprecipitation Assays. Naïve rats were euthanized under isoflurane anesthesia. The lumbar segments L3-L5 from whole spinal cords were ultrasonicated in ice-cold RIPA buffer (Beyotime, Shanghai, China). The supernatant after low-speed centrifugation was diluted with lysis buffer and adjusted to $2 \mathrm{mg} / \mathrm{mL}$. The cell suspensions passed through agarose resin served as controls. The sonicates were incubated overnight at $4^{\circ} \mathrm{C}$ with $\mathrm{PKC} \varepsilon$ and IgG primary antibody $(5 \mu \mathrm{L})$ to form immune complexes that were captured with fresh elution buffer and then incubated at $95^{\circ} \mathrm{C}$ for $6-$ $8 \mathrm{~min}$ in RIPA buffer. The mixture was centrifuged, and then, endogenous PKCE/STAT3 immune complexes in the supernatant were analyzed by Western blot analysis.

2.9. Cell Culture and Transfection. HEK293 cells (Shanghai Institutes for Biological Sciences, Shanghai, China) were cultured in Dulbecco's modified Eagle's medium (DMEM) containing $10 \%$ fetal bovine serum and $1 \%$ penicillin/streptomycin (Gibco; Thermo Fisher Scientific Inc., Waltham, MA USA) at $37^{\circ} \mathrm{C}$ in a $5 \% \mathrm{CO}_{2}$ incubator (Thermo Fisher Scientific Inc.). Various constructs were transfected into HEK293 cells using Lipofectamine 2000 (Invitrogen; Thermo Fisher Scientific Inc.) as described by the manufacturer.

Full-length PKCe and STAT3 were, respectively, cloned into pEGFP-C1 (Clontech Laboratories Inc., Mountain View, CA, USA) and pECMV-3X Flag-N (Biofeng, Beijing, China), then transfected into HEK293 cells. Two phosphorylation sites were mutated using point mutation technology to construct phenylalanine and alanine mutants STAT3 ${ }^{\mathrm{Y} 705 \mathrm{~F}}$ and STAT3 ${ }^{\text {Y727A }}$, respectively, which mimic dephosphorylated STAT3. The aspartic acid mutants STAT3 ${ }^{\text {Y705D }}$ and STAT3 mimic phosphorylated STAT3.

Extracts of transfected cells were quantified using BCA assay kits (Beyotime). Supernatants were diluted with lysis buffer and adjusted to $2 \mathrm{mg} / \mathrm{mL}$ of protein; then, $500 \mu \mathrm{L}$ portions were incubated overnight with $20 \mu \mathrm{L}$ of anti-Flag magnetic beads (Beyotime) at $4^{\circ} \mathrm{C}$. Immune complexes with magnetic beads were washed three times with lysis buffer, precipitated, then eluted from the beads by boiling with $30 \mu \mathrm{L}$ of SDS-PAGE loading buffer for 6-8 min. The eluate was centrifuged; then, proteins in the supernatant were analyzed by western blotting.

2.10. IL-6 Promoter Activity. The IL-6 promoter region $(-1500$ to +19$)$ was amplified by PCR and ligated into the pGL3 Basic vector (Biofeng). Full-length PKC $\varepsilon$ and STAT3 were cloned into pRL-null cells (Biofeng), then transfected into cultured HEK293 cells. The pGL3-IL-6 promoter $(0.5 \mu \mathrm{g})$, pRL-null (Renilla, $0.5 \mu \mathrm{g})$, pRL-STAT3 $(1 \mu \mathrm{g})$, and pRL-PKCE $(1 \mu \mathrm{g})$ expression vectors were cotransfected overnight into HEK293 cells. The transfected cells were incubated with $1 \mu \mathrm{g} / \mathrm{mL}$ lipopolysaccharide (LPS) for $12 \mathrm{~h}$, and then, IL- 6 promoter activity was assayed using dual luciferase kits (Jikai Gene Chemical Technology Co., Ltd., Shanghai, China).

2.11. Statistical Analysis. All data were presented as means \pm standard deviation (SD) and analyzed by one-way analysis of variance (ANOVA) followed by the Bonferroni tests using
SPSS 19.0 (IBM Corp., NY, USA). The graphs were constructed using the GraphPad Prism 7.0 software (GraphPad Software Inc., CA, USA). The statistical significance was set at $P<0.05$.

\section{Results}

3.1. Inhibiting Activated Neurocytes Alleviated Inflammatory Pain and IL-6-Induced Hyperalgesia. Two injections each of T-5224, Mino, and LAA, respectively, inhibited the activation of neurons, astrocytes, and microglia cells and generated immediate and prolonged anti-FCA-induced inflammatory pain in the model (Figure 2(a)). The AUC of T-5224, Mino, and LAA in the ipsilateral side paw of the FCA-induced inflammatory pain model was, respectively, $0.94 \pm 0.02,0.91 \pm 0.03$, and $0.94 \pm 0.02$ (Figure 2(b)). These agents did not affect the mechanical threshold in the paw that was not injected (Figure 2(c)).

A single intrathecal injection of IL-6 $(20 \mathrm{ng} / 50 \mu \mathrm{L})$ evoked transient, but significant, mechanical allodynia in the right hind paws of naïve rats. This was similar to the FCA-induced mechanical hypersensitivity and was reversed by T-5224, Mino, and LAA (Figure 2(d)). The AUC of T5224, Mino, and LAA was $0.87 \pm 0.05,0.87 \pm 0.05$, and $0.88 \pm 0.05$, respectively, in the right hind paws of the rats under IL-6-mediated hyperalgesia (Figure 2(e)). The analgesic effects of T-5224, Mino, and LAA were similar in the left hind paw under IL-6-induced hyperalgesia (Figure 2(f)).

3.2. T-5224, Mino, and LAA Decreased the Expression of cFos, GFAP, Iba-1, PKCE, and IL-6. T-5224, Mino, and LAA significantly decreased the expression of c-Fos, GFAP, and Iba-1, which were, respectively, the FCA-induced markers of neurons, astrocyte, and microglia activation in the spinal cord (Figures 3(a)-3(d)). The expression of PKC $\varepsilon$ and IL-6 in the spinal cord was also upregulated in FCA-treated rats (Figures 3(e) and 3(f)), whereas that of STAT3 did not differ among the groups (Figure $3(\mathrm{~g})$ ), indicating that the effects of T-5224, Mino, and LAA were exerted through the PKCe and IL-6 pathways, but not via the STAT3 signaling pathway.

3.3. Roles of PKCE, STAT3, and IL-6 in Inflammatory Pain and IL-6-Induced Hyperalgesia. We blocked the corresponding cellular signaling pathways using $\mathrm{PKC} \varepsilon$ inhibitor peptide, APTSTAT3-9R, and anti-IL-6 antibodies to determine the roles of PKCe, STAT3, and IL-6 in the pain process. Anti-IL-6 significantly increased mechanical threshold inflammatory pain on the ipsilateral, but not the contralateral, hind paw from the start of drug injection for up to 7 days, whereas PKCE inhibitor peptide and APTSTAT3-9R increased mechanical pain threshold from days 5-7 (Figure 4(a)). The AUC of PKC $\varepsilon$ inhibitor peptide, APTSTAT3-9R, and anti-IL-6 antibody was $0.73 \pm$ $0.05,0.66 \pm 0.06$, and $0.91 \pm 0.03$ in the ipsilateral side hind paw of the FCA-induced inflammatory pain model, respectively (Figure 4(b)). The intrathecal administration of T-5224, Mino, and LAA did not affect the FCAinduced mechanical threshold in the contralateral noninflamed paw (Figure 4(c)). 


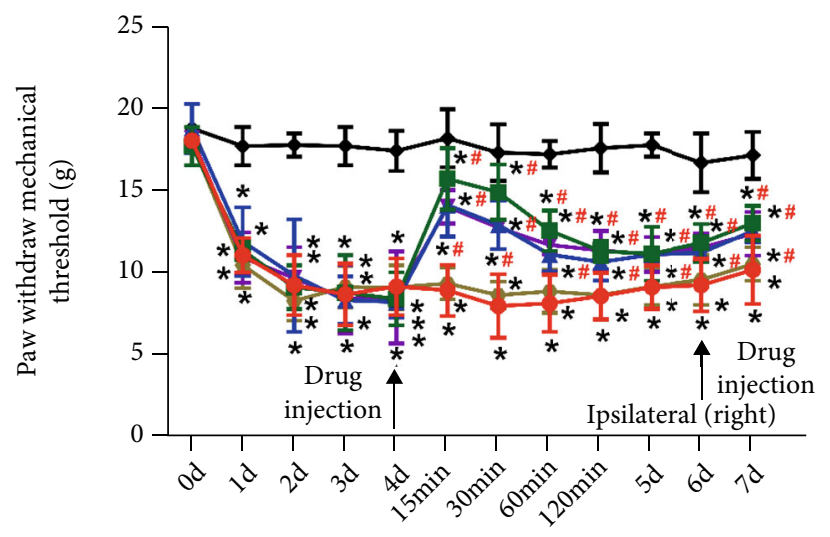

Post FCA injection (day)

$$
\begin{array}{ll}
\rightarrow-\text { Control } & - \text { FCA } \\
\rightarrow-\text { FCA+T-5224 } & - \text { FCA+Mino } \\
\rightarrow \text { FCA+LAA } & - \text { FCA+vehicle }
\end{array}
$$

(a)

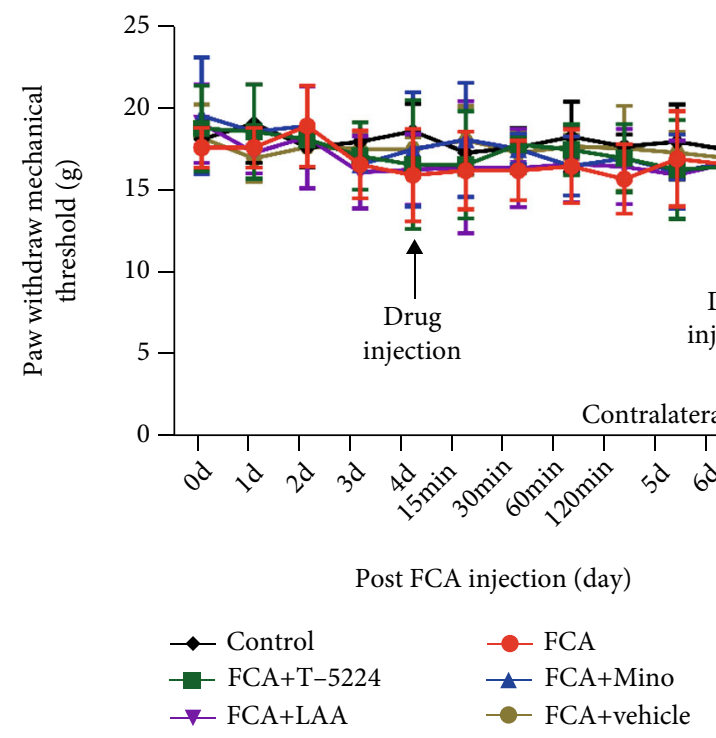

(c)

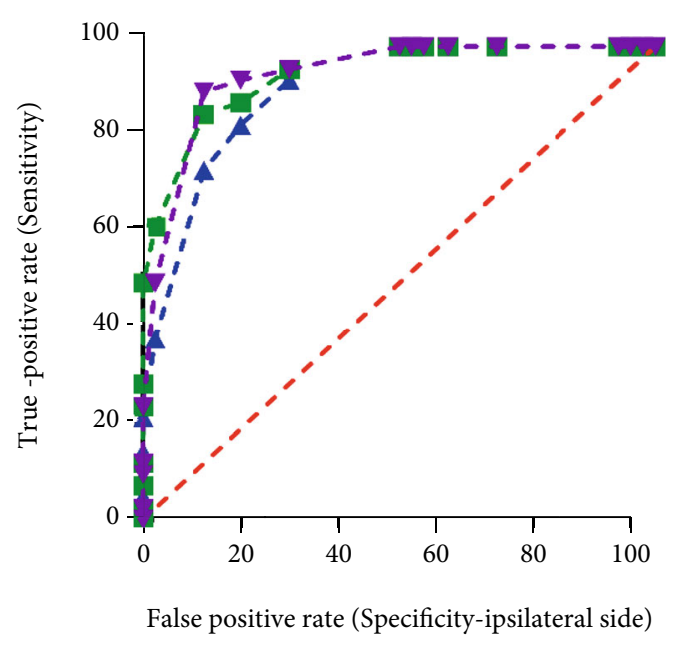

$-\square-$ FCA+T-5224 $($ Area $=0.9422)$
$-\mathbf{A}-$ FCA+Mino $($ Area $=0.9096)$
$-\nabla-$ FCA+LAA $($ Area $=0.9399)$

(b)

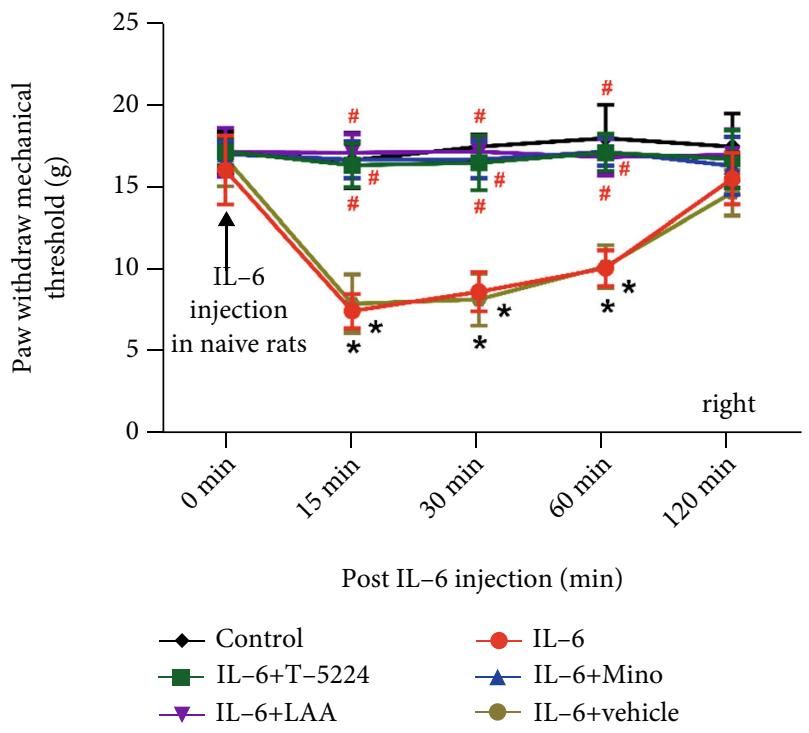

(d)

Figure 2: Continued. 


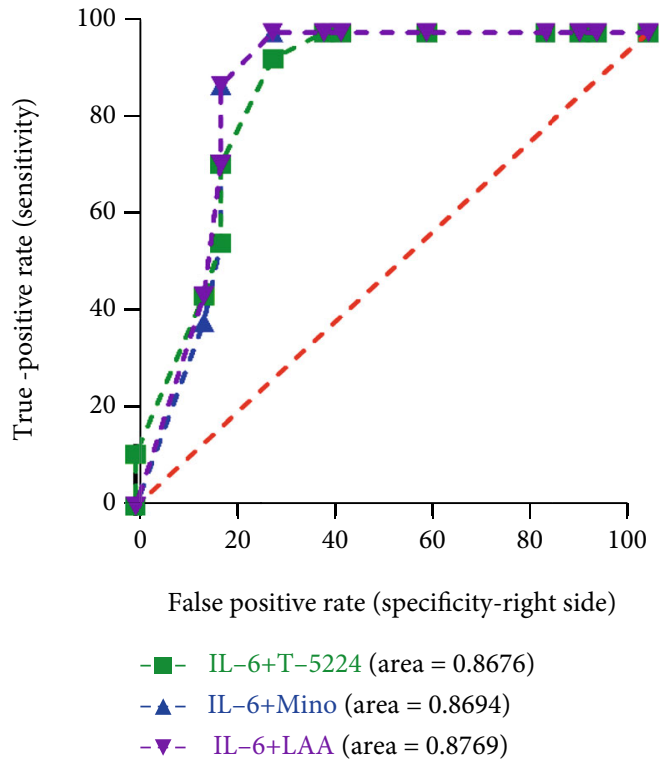

(e)

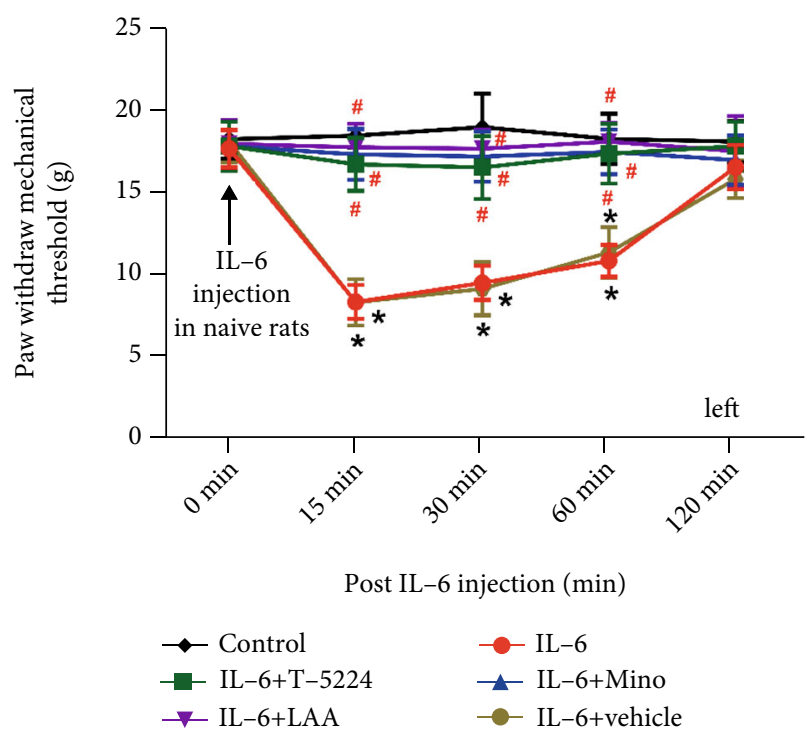

(f)

Figure 2: T-5224, Mino, and LAA ameliorated mechanical allodynia, inflammatory pain, and IL-6 induced hyperalgesia in rats. (a) Line plots indicate the effects of T-5224 (c-Fos/AP-1 inhibitor, $500 \mu \mathrm{g} / 50 \mu \mathrm{L}$ ), minocycline (Mino, $100 \mu \mathrm{g} / 50 \mu \mathrm{L}$ ), and L-2-aminoadipic acid (LAA, $1 \mathrm{mg} / 50 \mu \mathrm{L}$ ) on ipsilateral paw withdrawal mechanical thresholds (PWMTs) in FCA-induced inflammatory pain. ${ }^{*} P<0.05$ versus control. ${ }^{\#} P<0.05$ versus FCA; one-way ANOVA with Bonferroni tests. (b) ROC curves and AUC of T-5224, Mino, and LAA on the ipsilateral side of FCA-treated rats. (c) Intrathecal injection of T-5224, Mino, and LAA did not alter FCA-induced mechanical nociception on the contralateral noninflamed side $(P>0.05)$. $(\mathrm{d}, \mathrm{f})$ Interleukin-6 $(20 \mathrm{ng} / 50 \mu \mathrm{L})$ microinjection reversed T-5224-induced mechanical hyperalgesia $(500 \mu \mathrm{g} / 50 \mu \mathrm{L})$, Mino $(100 \mu \mathrm{g} / 50 \mu \mathrm{L})$, and LAA $(1 \mathrm{mg} / 50 \mu \mathrm{L})$ in the right and left hind paws of naïve rats; ${ }^{*} P<$ 0.05 versus control. ${ }^{\#} P<0.05$ versus IL-6, one-way ANOVA with Bonferroni tests. (e) ROC curves and AUC for T-5224, Mino, and LAA in the right hind paws of naïve rats. Data are shown as means $\pm \mathrm{SD}(n=6)$. AUC: area under receiver operator characteristic curves; ROC: receiver operator characteristic curve.

When these three conditions were applied to rats with IL-6-induced hyperalgesia, only anti-IL-6 improved the hypersensitivity and response to pain in the right paw (Figure 4(d)). The AUC of the PKCe inhibitor peptide, APTSTAT3-9R, and anti-IL-6 antibody was $0.64 \pm 0.08$, $0.64 \pm 0.08$, and $0.95 \pm 0.03$ in the right hind paw under IL-6-mediated hyperalgesia, respectively (Figure 4(e)). The analgesic effect of anti-IL-6 was similar in the left hind paw (Figure 4(f)).

3.4. PKCE Inhibitor Peptide, APTSTAT3-9R, and Anti-IL-6 Antibody Decreased the Expression of IL-6, c-Fos, GFAP, and $\mathrm{I} b a-1$. The $\mathrm{PKC} \varepsilon$ inhibitor peptide reduced $\mathrm{PKC} \varepsilon$ expression, and APTSTAT3-9R downregulated the spinal level of STAT3 (Figures 5(a)-5(c)). The PKC $\varepsilon$ inhibitor peptide, APTSTAT3-9R, and anti-IL-6 antibodies significantly decreased the spinal levels of phosphorylated STAT3 ${ }^{\text {Ser727 }}$ but not of STAT3 ${ }^{\text {Try705 }}$ and IL-6 (Figures 5(d)-5(f)). The expression of c-Fos, GFAP, and Iba-1 in the spinal cord was also decreased by the PKCe inhibitor peptide, APTSTAT3-9R, and anti-IL-6 antibody in rats with FCAinduced inflammatory pain (Figures $5(\mathrm{~g})-5(\mathrm{i})$ ).

3.5. Phosphorylation of STAT3 ${ }^{\text {Ser }} 727$ Increased STAT3 Interaction with $P K C \varepsilon$. The expression of PKCE/STAT3 in the dorsal horn of the spinal cord was significant decreased by PKCe or STAT3 inhibitor but not by anti-IL-6 antibody compared with that in the control and FCA groups (Figures 6(a)-6(f)).

Endogenous PKCE/STAT3 immunocomplexes in spinal cord tissues were assessed (Figure 7(a)). After incubating HEK293 cells with lipopolysaccharide (LPS), STAT3 increased IL-6 promoter activity, which was also enhanced in the presence of PKCE (Figure $7(\mathrm{~b})$ ). The STAT3 ${ }^{\mathrm{Y} 727 \mathrm{D}}$ phosphomimetic mutant had more affinity for PKCe, whereas the other mutants generated results similar to those of wild-type STAT3, indicating that the phosphorylation at Ser727 increased the ability of STAT3 to bind to PKCE (Figures 7(c) and 7(d)).

\section{Discussion}

Our results showed that FCA-induced inflammatory pain and IL-6-induced hyperalgesia were alleviated by inhibiting neurocyte activation or by anti-IL- 6 therapy, indicating that IL-6 participated in the maintenance of inflammationinduced nociception. This study was novel in demonstrating that T-5224, Mino, and LAA inhibited FCA-induced inflammatory pain and IL-6-induced hyperalgesia, despite previous findings of the therapeutic effects of Mino against chronic bone cancer pain and chronic pain $[19,20]$. 


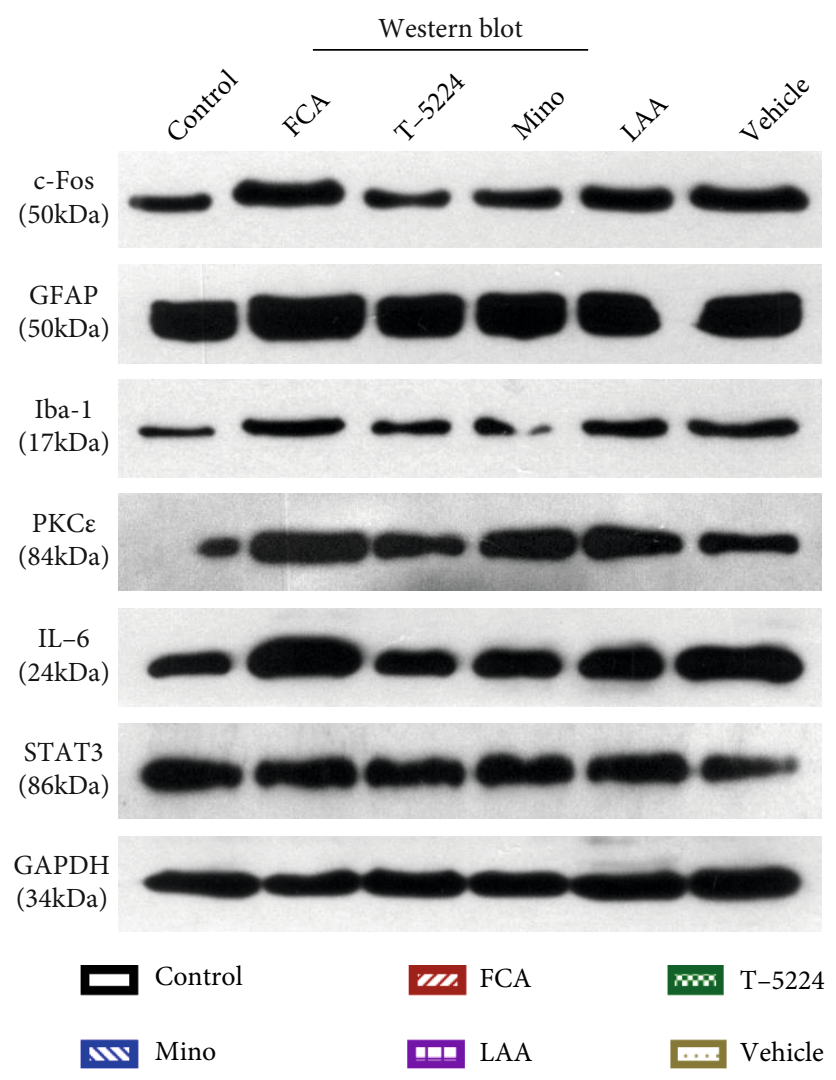

(a)

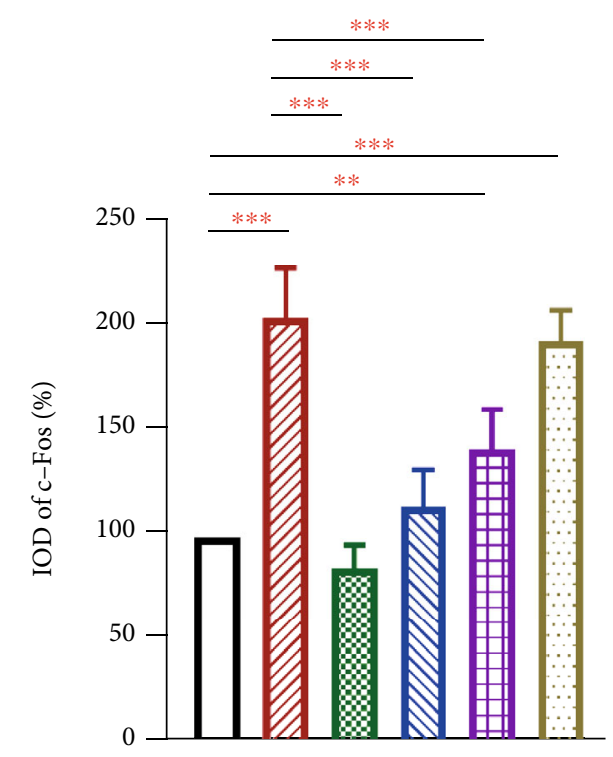

(b)

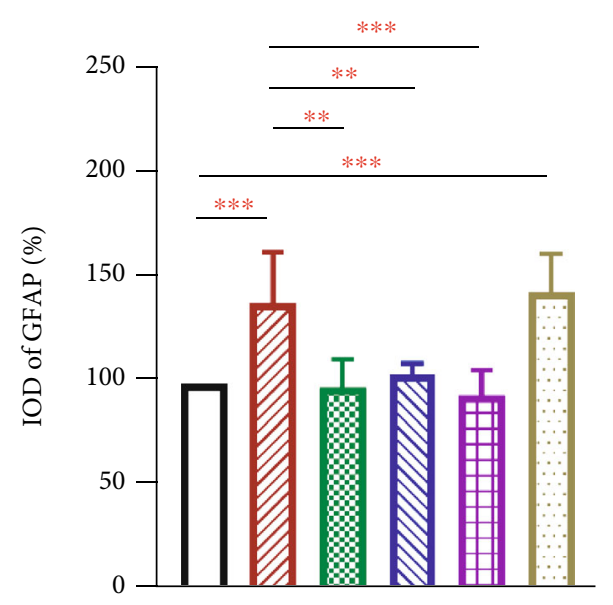

(c)

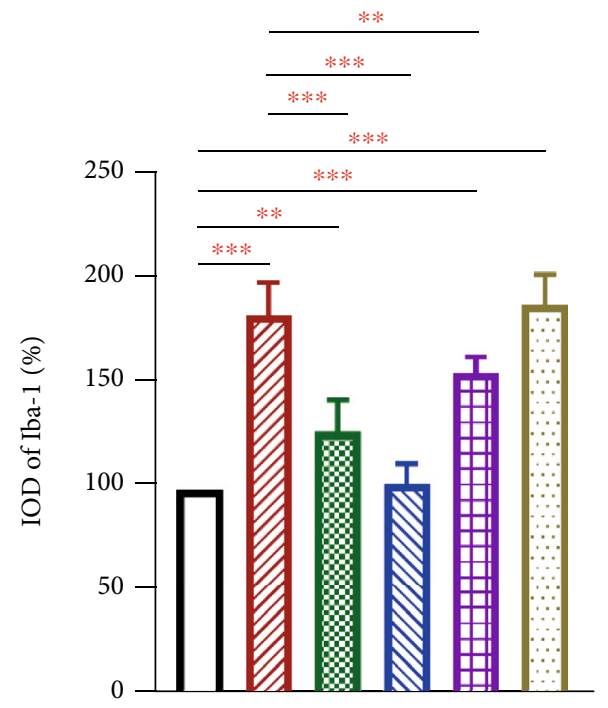

(d)

Figure 3: Continued. 


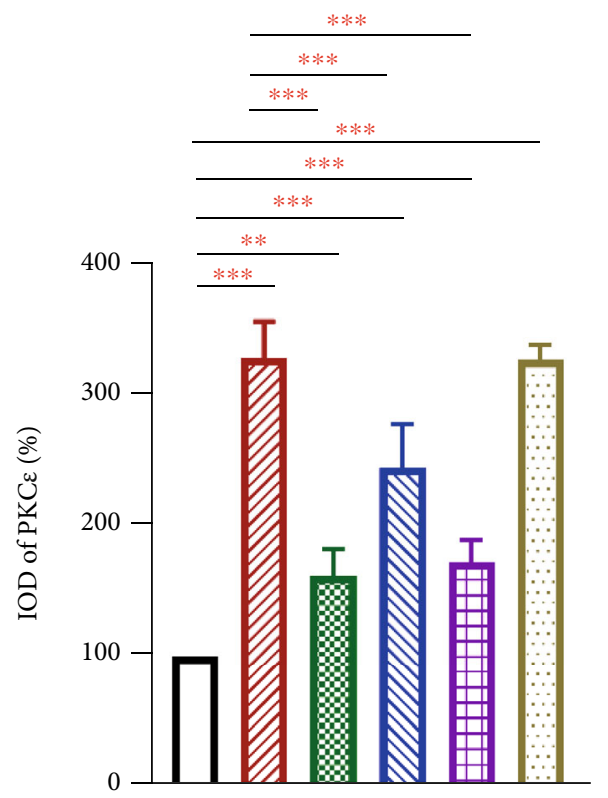

(e)

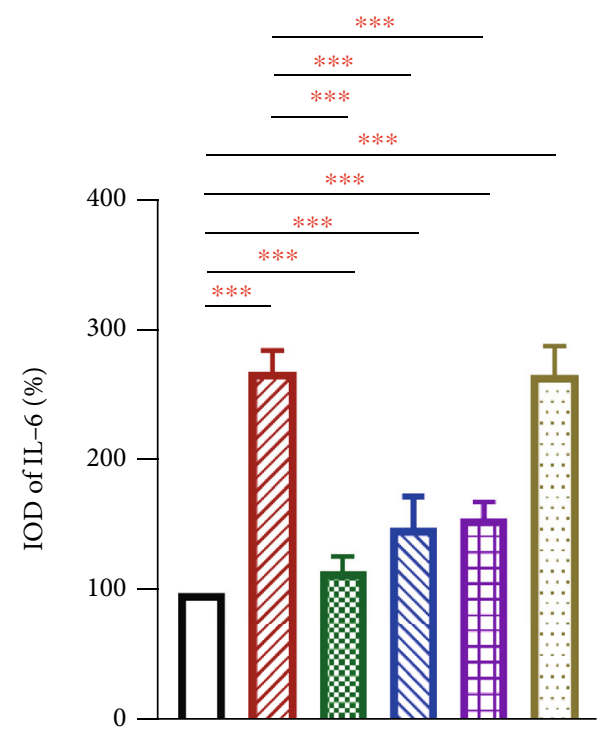

(f)

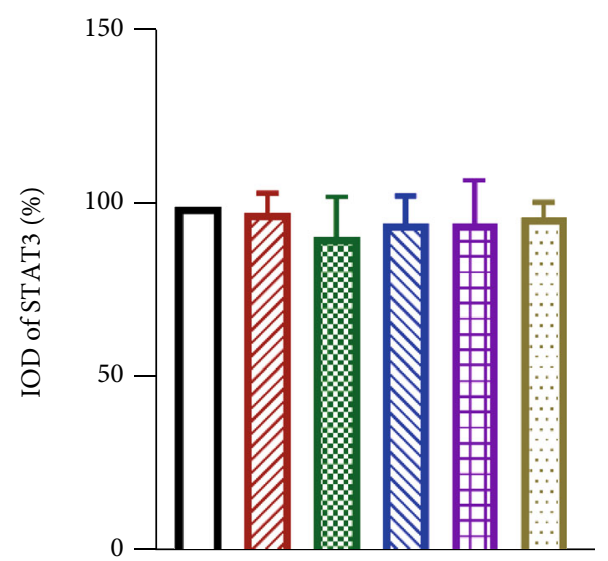

(g)

FIGURE 3: Western blot analysis of the proteins related to activated neurocytes during inflammatory pain. Examples (a) and mean values (bg) of c-Fos, GFAP, Iba-1, PKCe, STAT3, and IL-6 proteins in the spinal cord. Intrathecally injected T-5224 (c-Fos/AP-1 inhibitor, $500 \mu \mathrm{g} /$ $50 \mu \mathrm{L}$ ), minocycline (Mino, $100 \mu \mathrm{g} / 50 \mu \mathrm{L}$ ), and L-2-aminoadipic acid (LAA, $1 \mathrm{mg} / 50 \mu \mathrm{L}$ ) reduced c-Fos, GFAP, Iba-1, PKC $\varepsilon$, and IL-6 protein levels in FCA-treated rats, whereas STAT3 expression did not change between groups $(P>0.05)$. Data were normalized against GAPDH and are expressed as ratios (\%) of control. Data are shown as means $\pm \mathrm{SD}(n=4-5) .{ }^{*} P<0.05,{ }^{* *} P<0.01$; ${ }^{* * *} P<0.001$, oneway ANOVA with Bonferroni tests.

The present study used an inflammatory pain model created by unilateral injections of FCA or intrathecal injections of IL-6 that induced hyperalgesia in rats. The mechanical paw withdrawal threshold was significantly reduced for up to 7 days by FCA and up to 60 min by IL-6. An intraplantar injection of FCA induced central sensitization and increased the levels of pain mediators, including IL-6, peripherally and centrally, whereas the intrathecal injection of IL-6 likely resulted in transient central sensitization due to a local increase in pain mediators per se $[6,21]$.

We found that T-5224, Mino, and LAA decreased the expression levels of c-Fos, GFAP, Iba-1, PKCe, and IL-6 but did not alter STAT3 levels during the FCA-induced inflammatory process (Figure 3 ). Our results indicated that the inhibition of neurocyte activation reduced IL-6mediated pain sensitivity, which was in line with previous findings of the crosstalk between activated neurocytes and IL-6-induced pain $[3,6,16,22,23]$. However, the analgesic effects of T-5224, Mino, and LAA were associated with other cytokines such as IL-1 $\beta$ and TNF- $\alpha$ [24], suggesting that activated neurocytes comprised a control mechanism of inflammatory pain [25].

We further examined the roles of PKC $\varepsilon$, STAT3, and IL6 in FCA-induced inflammatory pain and IL-6-induced hyperalgesia. Anti-IL-6 immediately alleviated inflammatory pain for an extended period and reversed the hyperalgesic effects of IL-6 (Figure 4), suggesting that IL-6 was a potent pain mediator. In contrast, the PKC $\varepsilon$ inhibitor peptide and 


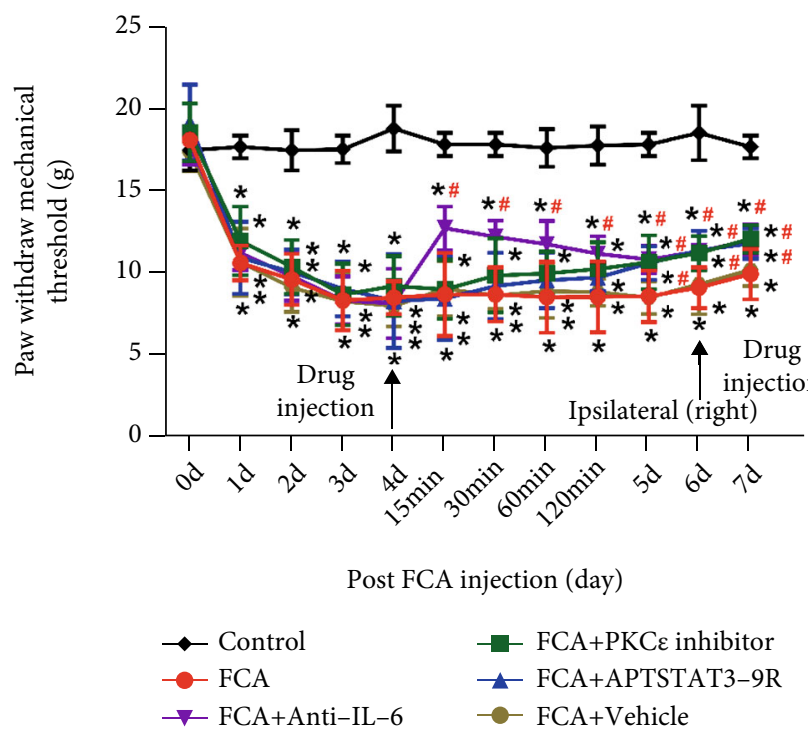

(a)

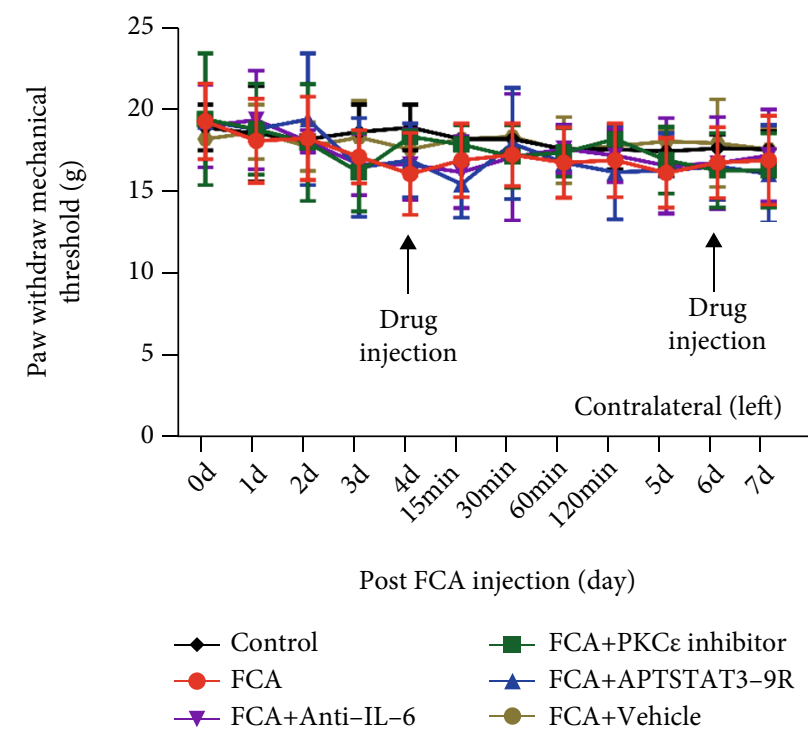

(c)

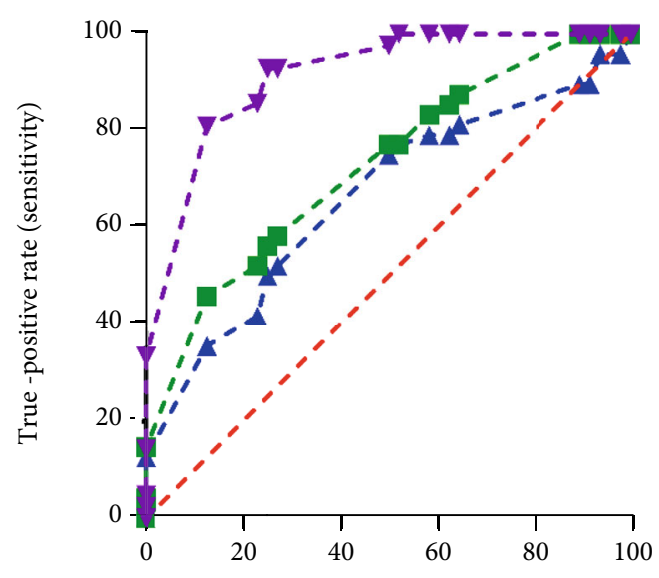

False positive rate (specificity-ipsilateral side)

- - FCA+PKC inhibitor $($ Area $=0.7250)$

- $\mathbf{-}$ - IL-6+APTSTAT3-9R $($ Area $=0.6621)$

$-\nabla-$ FCA+Anti-IL-6 $($ Area $=0.9142)$

(b)

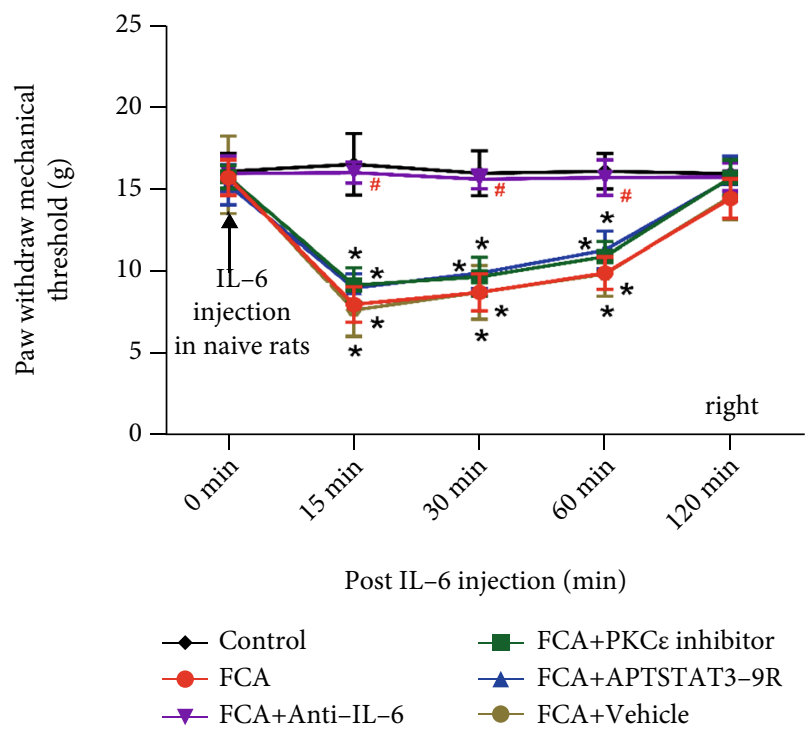

(d)

FIgURE 4: Continued. 


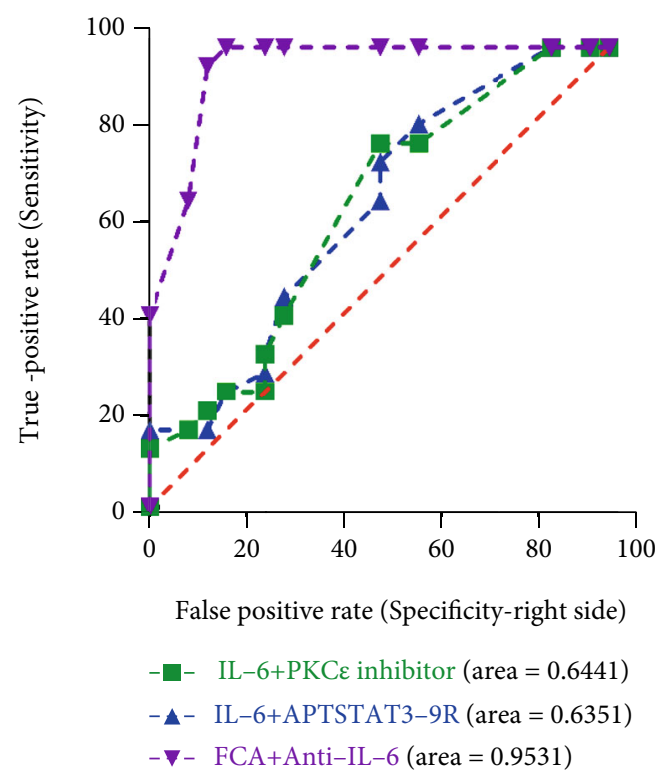

(e)

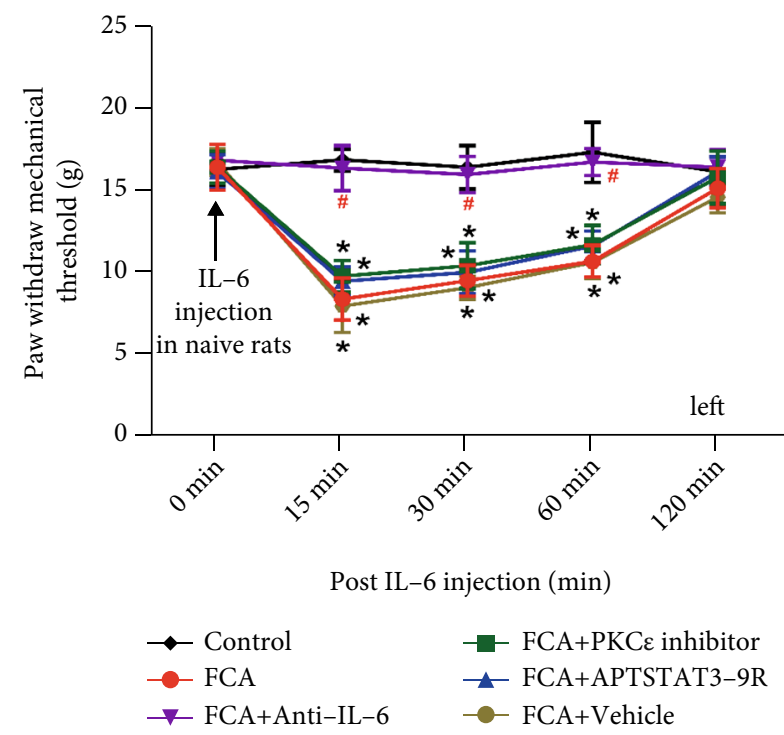

(f)

FIGURE 4: Evaluation of paw withdrawal mechanical threshold (PWMT) in rats with inflammatory pain and IL-6-induced hyperalgesia after the administration of PKCe inhibitor peptide, APTSTAT3-9R (STAT3 inhibitor), or anti-IL-6 antibody. (a) Anti-IL-6 antibody (100 ng/ $50 \mu \mathrm{L})$ rapidly attenuated FCA-induced pain for several days on the ipsilateral inflamed side. PKCe inhibitor peptide $(100 \mu \mathrm{g} / 50 \mu \mathrm{L})$ and APTSTAT3-9R $(20 \mu \mathrm{g} / 50 \mu \mathrm{L})$ exerted antinociceptive effects $24 \mathrm{~h}$ after drug injection. ${ }^{*} P<0.05$ versus control. ${ }^{*} P<0.05$ versus FCA, one-way ANOVA followed by Bonferroni tests. (b) ROC curves and AUC of PKCe inhibitor peptide, APTSTAT3-9R, and anti-IL-6 on the ipsilateral side of FCA-treated rats. (c) None of the PKCe inhibitor peptide, APTSTAT3-9R, and anti-IL-6 affected contralateral mechanical paw withdrawal thresholds in rats with FCA-induced inflammatory pain. (d, f) Interleukin-6 $(20 \mathrm{ng} / 50 \mu \mathrm{L})$ microinjected $10 \mathrm{~min}$ after naïve rats were injected with PKCe inhibitor peptide $(100 \mu \mathrm{g} / 50 \mu \mathrm{L})$ or APTSTAT3-9R $(20 \mu \mathrm{g} / 50 \mu \mathrm{L})$ did not affect IL-6induced mechanical hyperalgesia, whereas anti-IL-6 antibody $(100 \mathrm{ng} / 50 \mu \mathrm{L})$ did. ${ }^{*} P<0.05$ versus control. ${ }^{\#} P<0.05$ versus IL-6, one-way ANOVA followed by Bonferroni tests. (e) ROC curves and AUC of PKCe inhibitor peptide, APTSTAT3-9R, and anti-IL-6 in the right hind paws of naïve rats. Data are shown as means \pm SD $(n=6)$. AUC: area under receiver operating characteristic curve; ROC: receiver operator characteristics curve.

the STAT3 inhibitor did not exert immediate analgesic effects but elicited a mild, sustained analgesic effect for 5-7 days at the end of the experimental period. This phenomenon was accompanied by a decrease in the pSTAT3 ${ }^{\text {Ser727 }}$ level but not in the levels of pSTAT3 ${ }^{\text {Tyr705 }}$, IL-6, c-Fos, GFAP, and Iba-1 in the spinal cord, indicating that the upstream effectors PKCE and STAT3 regulated the formation of IL-6, thus mediating the activation of neurocytes (Figures 5 and 8). These findings were comparable with the association of PKC $\varepsilon$ and STAT3 levels with the IL-6 level and neurocytes [26-30]. PKCE and STAT3 regulated the production of IL-6, and pSTAT3 ${ }^{\text {Ser727 }}$ formed complexes with PKCe and enhanced STAT3 localization to the IL-6 promoter, thus increasing IL-6 expression [31]. The decrease in the levels of pSTAT3 and IL-6 in cells incubated with APTSTAT3-9R and anti-IL-6 suggested that STAT3 was involved in a negative feedback loop in the IL-6-induced signaling pathway per se.

PKCE and STAT3 interacted under physiological and pathological conditions [11,31]. Our immunofluorescence results also revealed the coexpression of PKCE and STAT3 in cells in the spinal cord (Figure 6), suggesting that PKCe together with STAT3 contributed to IL-6 production and the activation of neurons, astrocytes, and microglia during inflammation. Alone, PKCe did not affect the activity of the IL- 6 promoter; but IL- 6 promoter activity was increased more in the presence of both PKC $\varepsilon$ and STAT3 than that in the presence of STAT3 alone under LPS stimulation (Figure 7), suggesting that $\mathrm{PKC} \varepsilon$ increased the ability of STAT3 to bind to the IL-6 promoter. The immunoprecipitation results in vitro showed that the pSTAT3 ${ }^{\operatorname{Ser} 727}$ but not pSTAT3 ${ }^{\text {Tyr705 }}$ affected the interactions between PKC $\varepsilon$ and STAT3 (Figure 7), suggesting that pSTAT3 ${ }^{\text {Ser727 }}$ regulated the formation of PKCE/STAT3 complexes, thus influencing IL-6-mediated inflammatory pain.

Given the analgesic effect of T-5224, Mino, and LAA, they may serve as the potential therapeutic agents for inflammatory pain-related disease. This needs further discussion to understand the potential pharmacological characteristics of these compounds. T-5224 was first designed to inhibit the arthritis upstream of inflammatory cytokine and matrix metalloproteinase action [32]. It can be used in human articular chondrocytes, resulting in the inhibition of transactivation of downstream matrix metalloproteinases and inflammatory cytokines (including IL-6, IL$1 \beta$, and TNF- $\alpha$ ) and effectively preventing cartilage destruction and osteophyte formation in an osteoarthritisinduced mouse model [33]. T-5224 was also found to be 


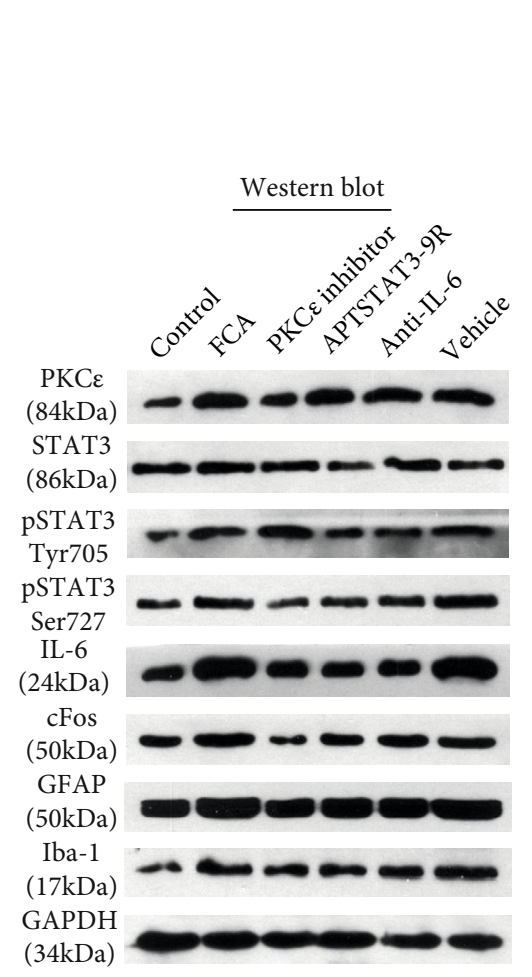

(a)

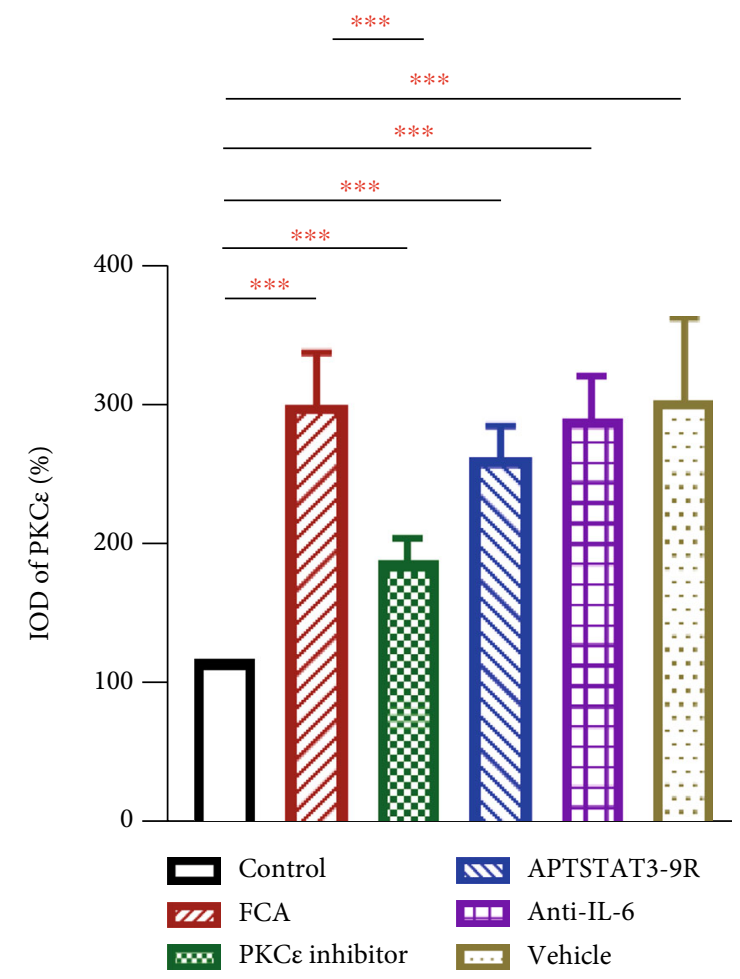

(b)

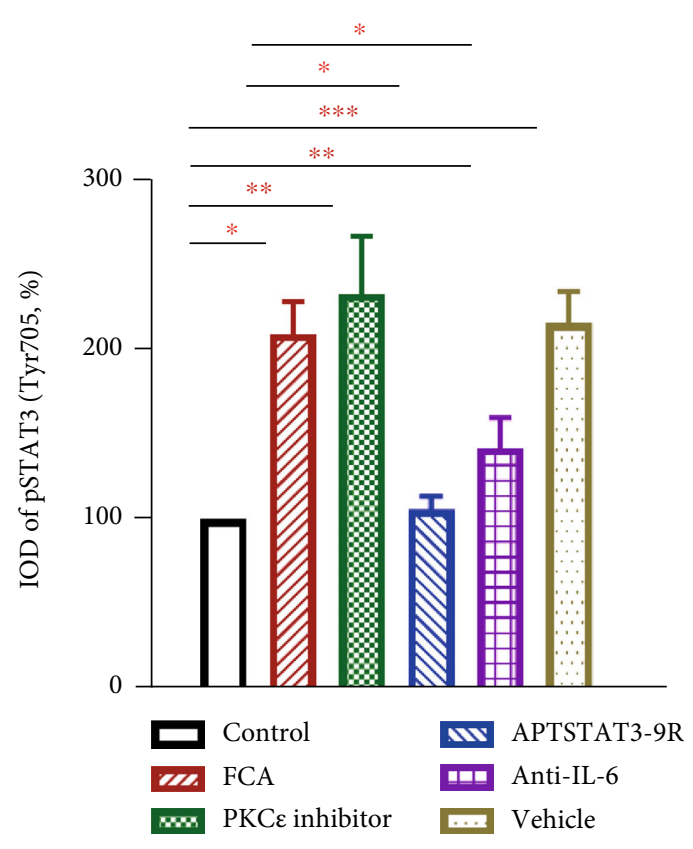

(d)

Figure 5: Continued. 


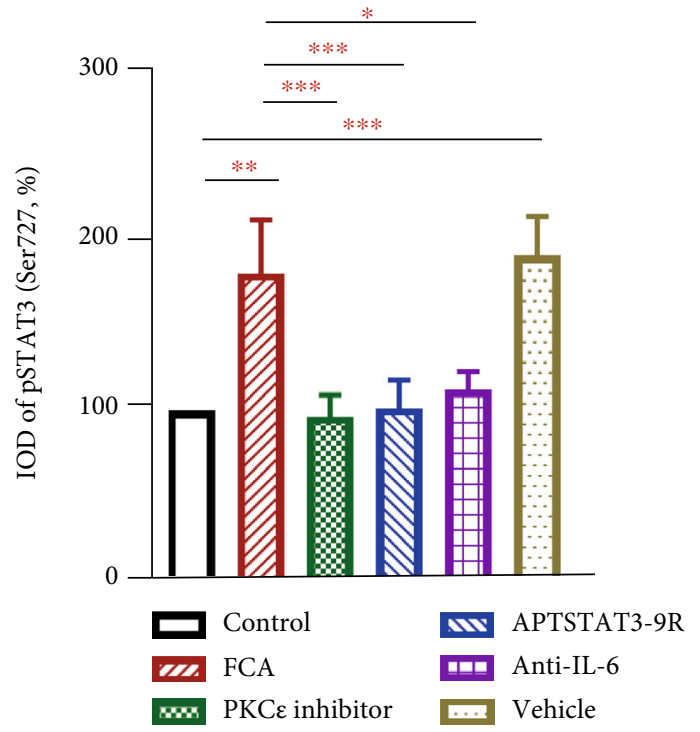

(e)

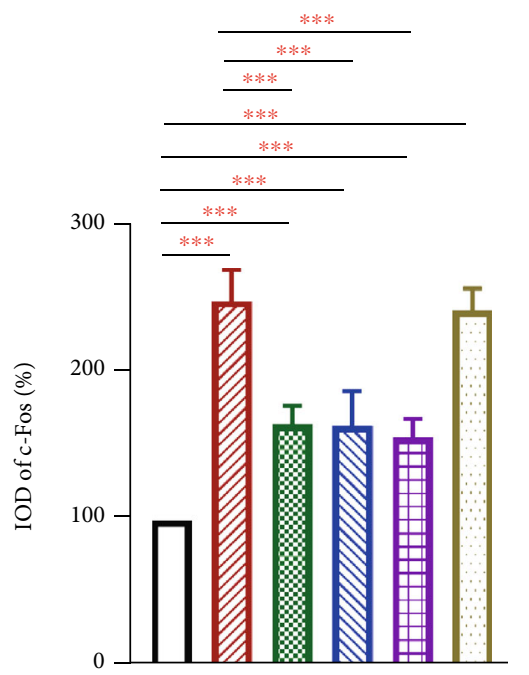

(g)

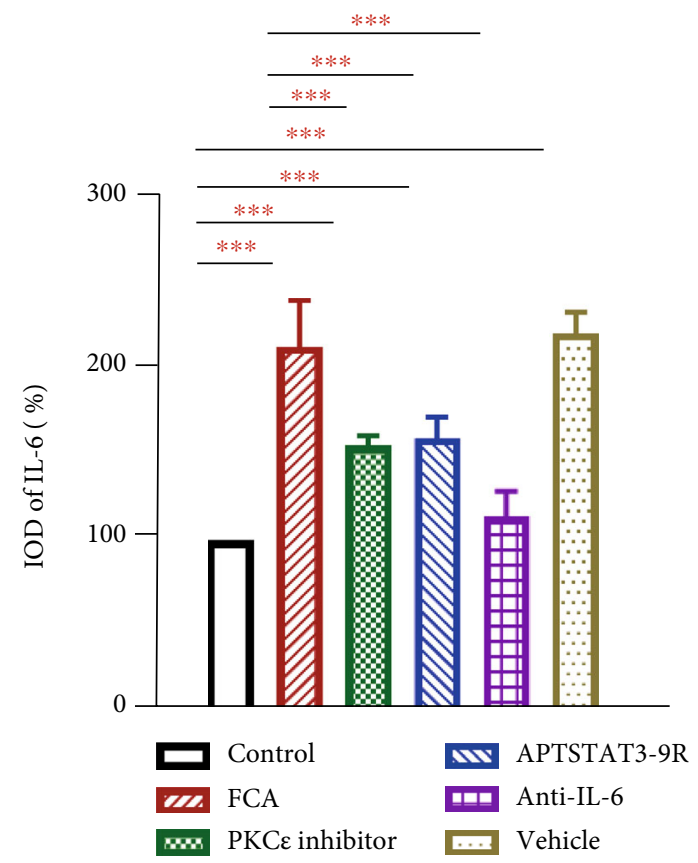

(f)

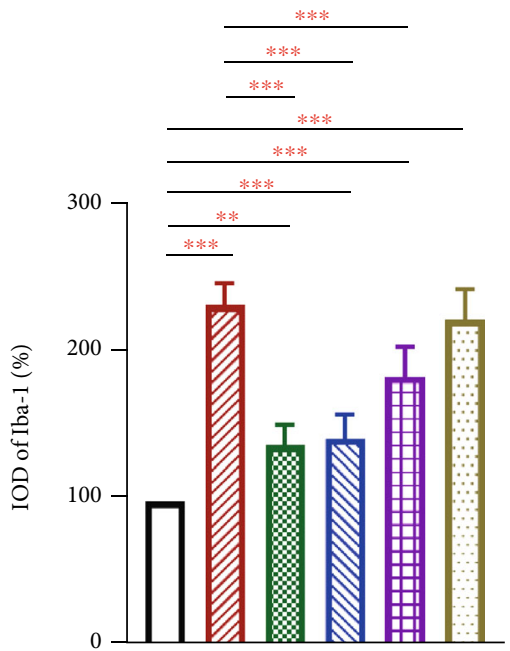

(i)

FIGURE 5: Expression of proteins related to activated neurocytes detected by Western blot analysis. (a-i) Protein expression of pSTAT3 (Ser727), IL-6, c-Fos, GFAP, and Iba-1 in the spinal cords of FCA-treated rats significant decreased $(P<0.05)$ after intrathecal injections of PKCE inhibitor peptide $(100 \mu \mathrm{g} / 50 \mu \mathrm{L})$, APTSTAT3-9R $(20 \mu \mathrm{g} / 50 \mu \mathrm{L})$, and anti-IL-6 antibody $(100 \mathrm{ng} / 50 \mu \mathrm{L})$. Values were normalized against GAPDH and are expressed as ratios (\%) of control values. Data are shown as means $\pm \operatorname{SD}(n=4-5) .{ }^{*} P<0.05,{ }^{* *} P<0.01,{ }^{* * *} P$ $<0.001$; one-way ANOVA followed by Bonferroni tests.

used in acute myeloid leukemia [34], mast cell [35], and triple negative breast cancer [36], which might serve as a synergistic therapeutic strategy for the clinical diseases; however, T-5224 is still in the preclinical stage. Hence, the data related to pharmacokinetics are lacking; more research and evidence are needed in the future. Mino is a semisynthetic tetracycline antibiotic with anti-inflammatory properties, which is used to treat multiple inflammatory diseases and could be safely applied in the clinical setting, such as Parkinson's disease [37] and neurodegenerative and psychiatric diseases [38] as well as the cerebral ische- mia [39]. It is generally well tolerated, and skin-related complaints, nausea, and dizziness are the most common patient-reported side effects [40]. LAA, a selective astrocytic toxin, has been demonstrated to exert some regulatory effects on tibia fracture [41], myotubes [42], and retina [43], thus contributing to the fracture-induced nociceptive, cell autophagy in myotubes, and retinal vascular responses. It has not yet been clinically applied due to its unusual astroglial toxin, which may trigger locomotor network damage. How to reduce the toxicity of LAA to central and peripheral nerves to the minimum is worth exploring [44]. 

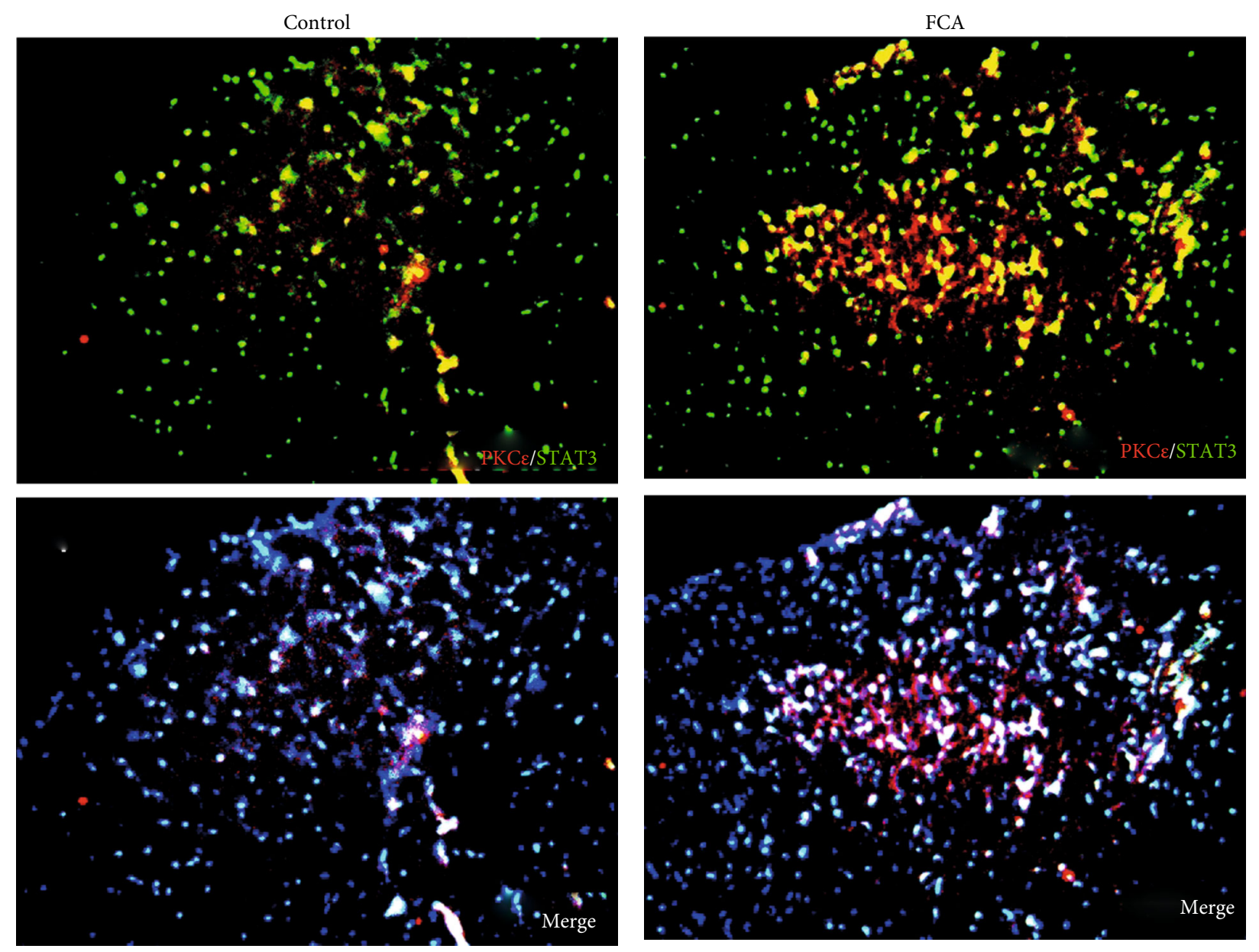

(a)

(b)

Figure 6: Continued. 
$\mathrm{PKC} \varepsilon$ inhibitor
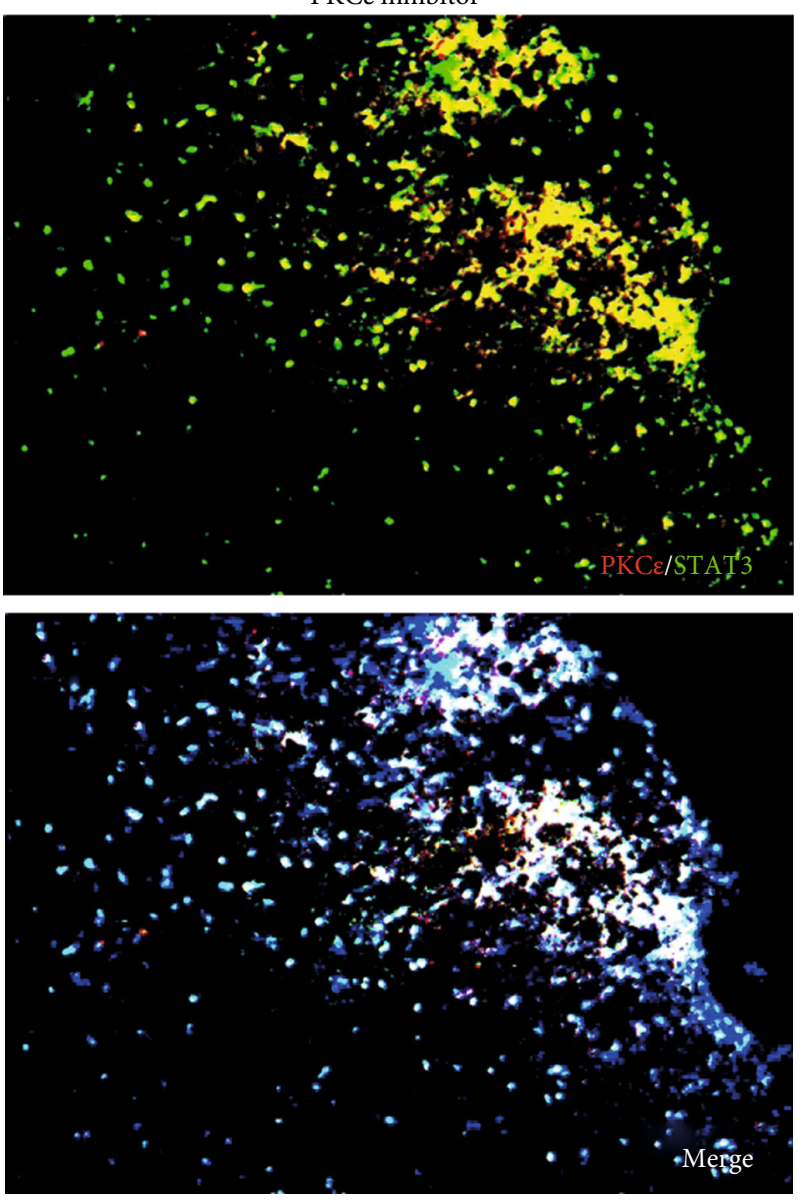

(c)
APTSTAT3-9R
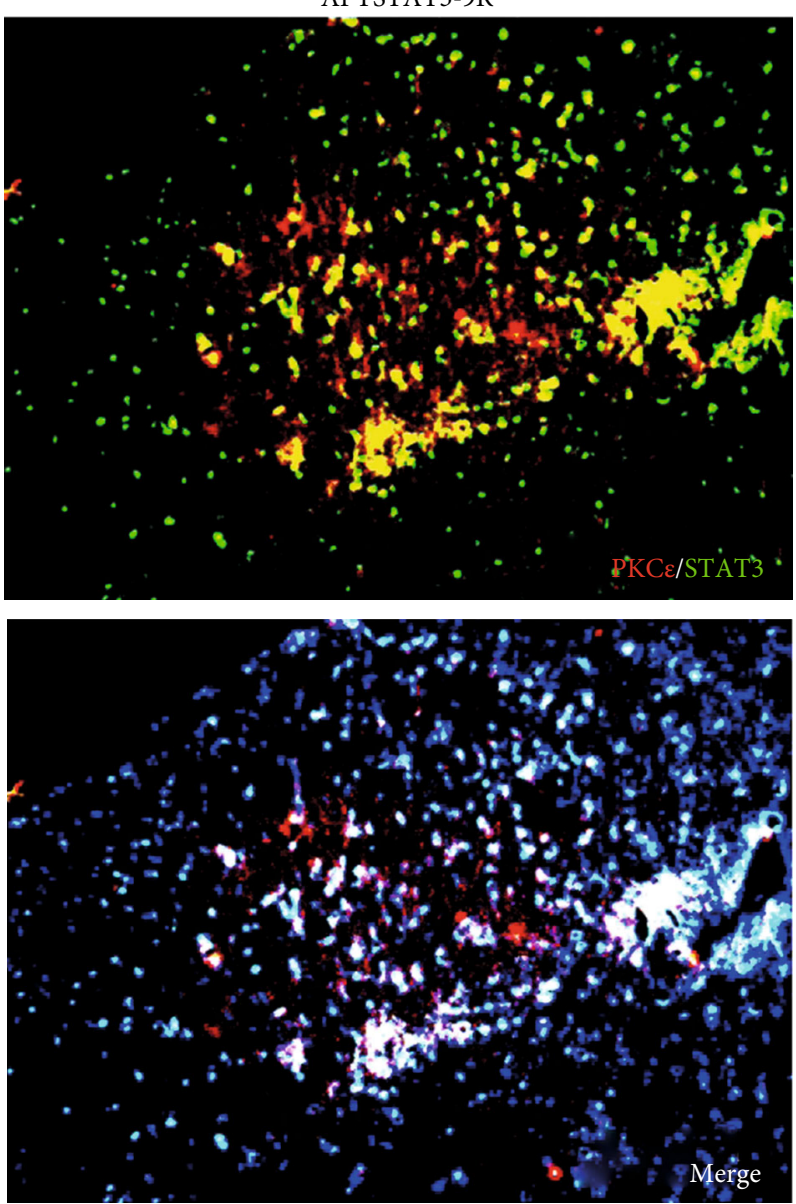

(d)

Figure 6: Continued. 
Anti-IL-6
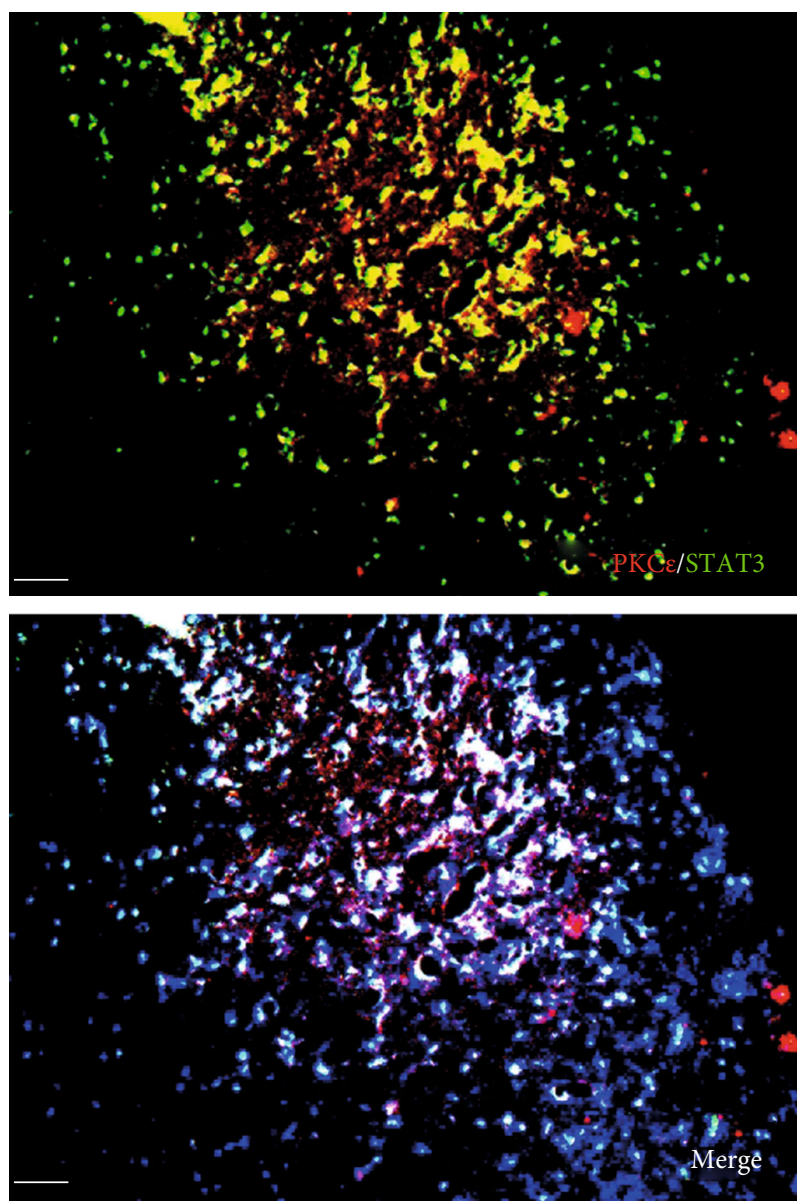

(e)
Vehicle
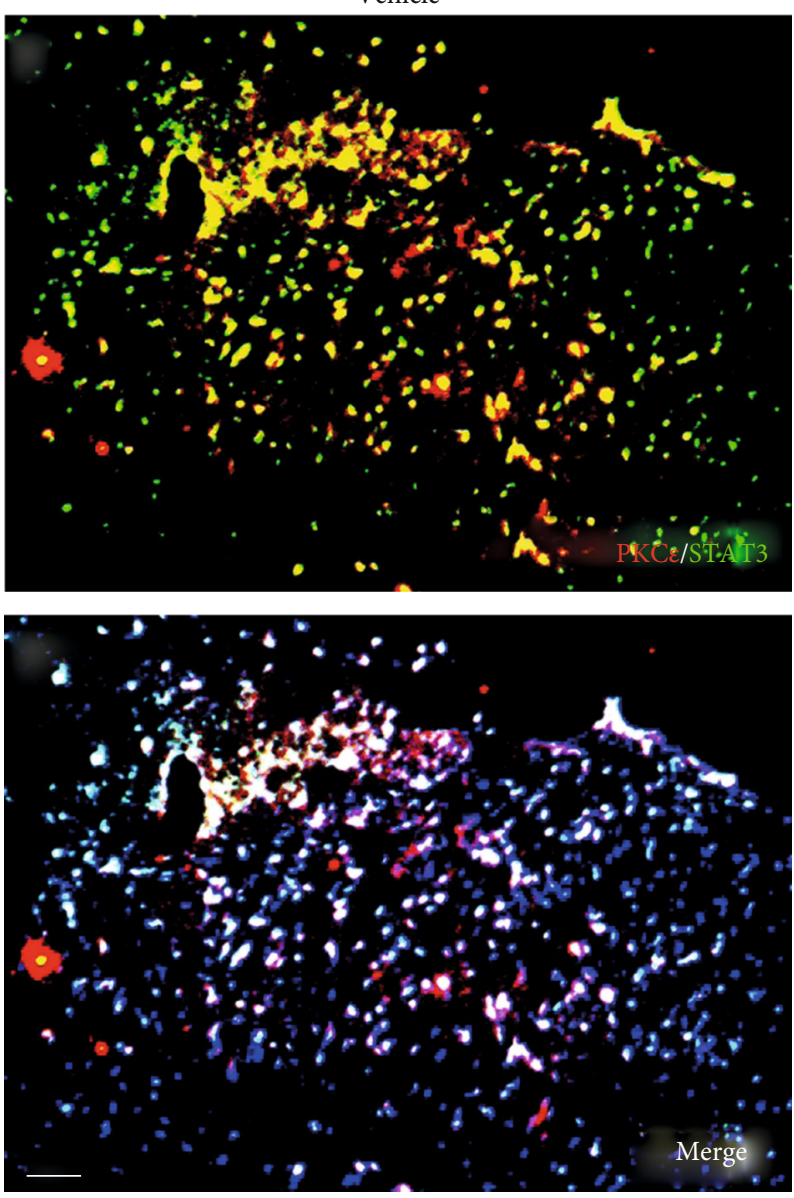

(f)

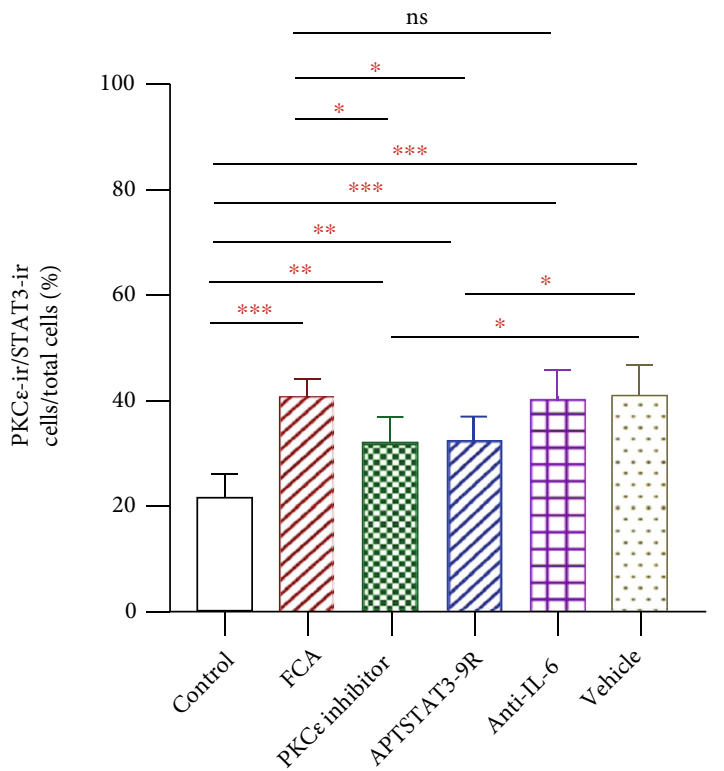

(g)

FIGURE 6: Detection of PKCe and STAT3 coexpression in vivo and their immune complexes in vitro. (a-f) Immunofluorescence staining for PKC $\varepsilon$ (red) and STAT3 (green) coexpression (yellow) and DAPI (blue in merged image) in spinal cord sections (a-e). Ratios of cells with immunoreactive PKCE-/STAT3 among total cells. (f) Inhibitors of PKC $\varepsilon$ and STAT3 significantly decreased the coexpression of PKCE/ STAT3 after APTSTAT3-9R administration. Bar $=40 \mu \mathrm{m}$. Data are shown as means \pm SD $(n=6) .{ }^{*} P<0.05,{ }^{* *} P<0.01,{ }^{* * *} P<0.001$; one-way ANOVA followed by Bonferroni tests. 


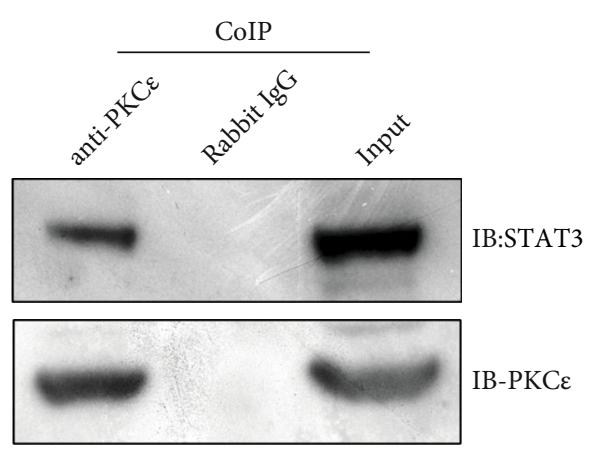

(a)

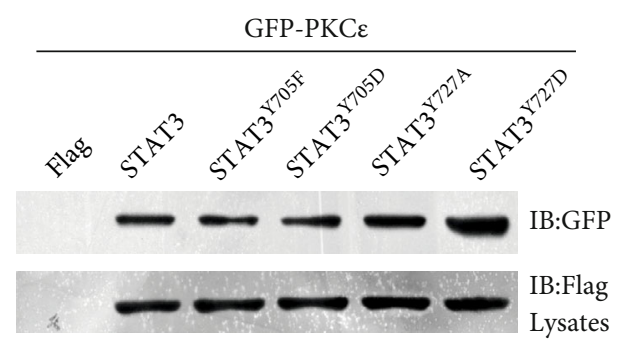

(c)

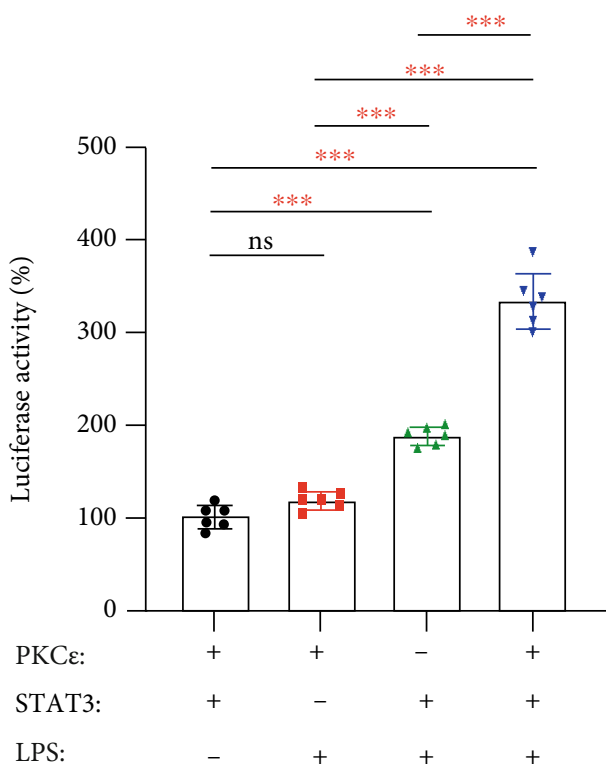

(b)

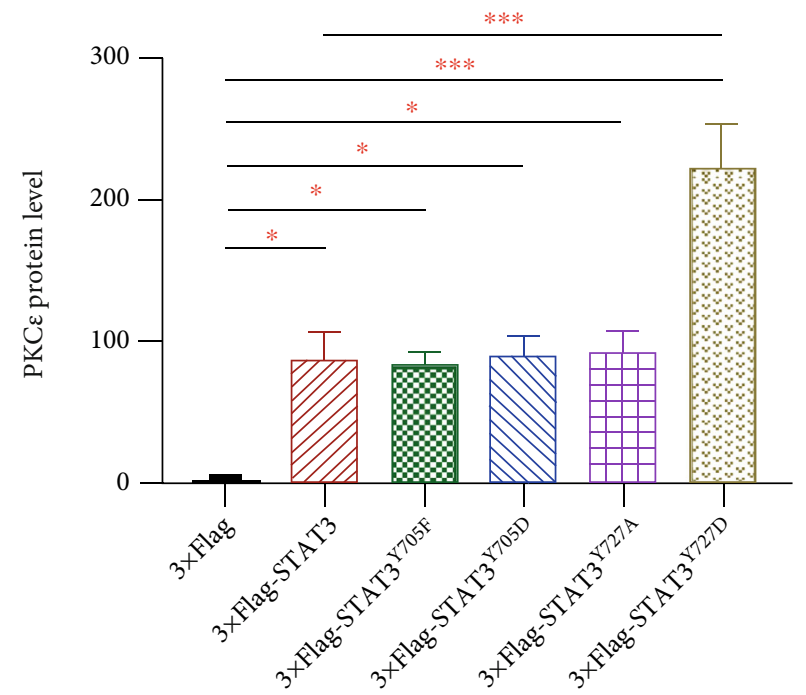

(d)

FIgURE 7: Ser727 of STAT3 increased its interaction with PKCe. (a) Endogenous PKCe was immunoprecipitated from cell lysates, and immune complexes and total cell lysates were analyzed by Western blot analysis with PKC $\varepsilon$ and STAT3 antibodies. Endogenous immune PKC $\varepsilon / S T A T 3$ complexes were detected in the rat spinal cord tissues. (b) IL-6 promoter-firefly luciferase reporter plasmid (0.5 $\mu \mathrm{g})$, PKC $\varepsilon$ $(1 \mu \mathrm{g})$, and STAT3 $(1 \mu \mathrm{g})$ were cotransfected overnight into HEK293 cells. The transfected cells were incubated with $1 \mu \mathrm{g} / \mathrm{mL}$ lipopolysaccharide (LPS) for $12 \mathrm{~h}$. Interleukin-6 promoter activity increased by STAT3 was further enhanced by PKCE and STAT3, indicating that PKCe improved the ability of STAT3 to bind to IL-6 promoter. Data are shown as means $\pm \mathrm{SD}(n=6)$. ${ }^{*} P<0.05,{ }^{* *} P<$ $0.01,{ }^{* *} P<0.001$; one-way ANOVA followed by Bonferroni tests. (c, d) HKE293 cells were transfected with GFP, GFP-PKCe, Flag, Flag-STAT3, and phosphomimetic and dephosphomimetic mutants of STAT3, and then, immunoprecipitants were assayed. Protein complexes were detected using an anti-GFP antibody (c), and then, relative PKCE binding to STAT3 was quantified (d). Data are presented as means $\pm \mathrm{SD}(n=3) .{ }^{*} P<0.05,{ }^{* *} P<0.01,{ }^{* * *} P<0.001$; one-way ANOVA followed by Bonferroni tests.

This study had some limitations. It focused only on IL-6-induced pain, and thus, its clinical relevance is debatable. However, early and delayed IL-6 elevation is associated with chronic neuropathic pain [45]. Interleukin-6 plays a key role in the chronic inflammation associated with rheumatoid arthritis (RA), and blocking IL-6 signaling is an important strategy in treating RA-associated dis- eases clinically [46]. Moreover, targeting IL-6 might be an option for treating other chronic inflammatory diseases [47]. Therefore, an in-depth understanding of how IL-6 induces cellular signaling that causes pain, and the development of new analgesic strategies associated with IL-6, have theoretical and clinical significance for pain management. 


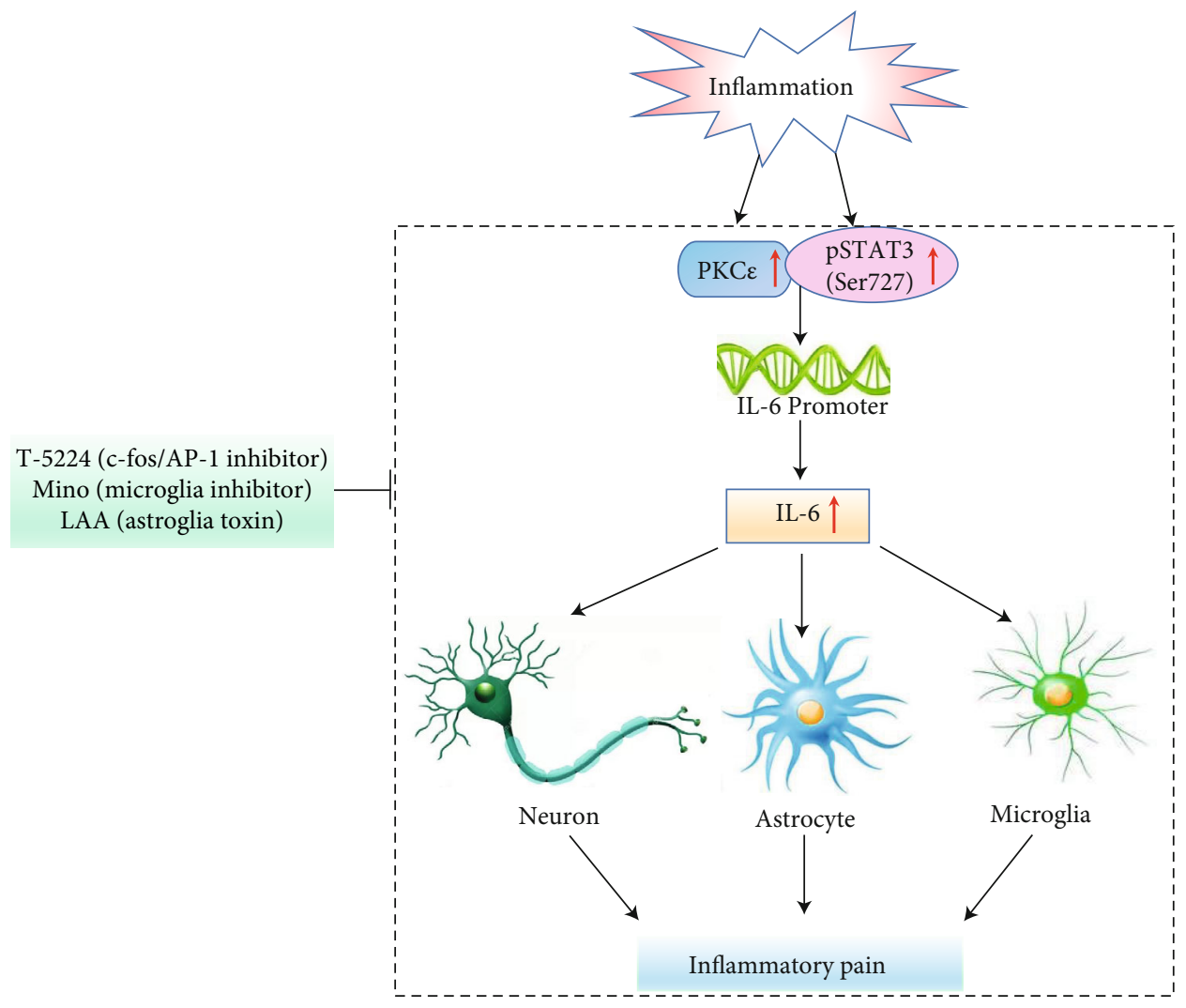

FIGURE 8: Interaction between PKC $\varepsilon$ and STAT3 ${ }^{\text {Ser727 }}$ in nociceptive regulation during inflammatory pain. PKC $\varepsilon$ and STAT3 engaged with IL-6-mediated neuronal and glial cell crosstalk during inflammatory nociceptive transmission. Under inflammatory conditions, upregulated PKC $\varepsilon$ and STAT $3^{\text {Ser727 }}$ phosphorylation interacted in the spinal cord and subsequently increased IL- 6 promoter activity that manifested as IL-6 cytokine-mediated inflammatory pain. T-5224, Mino, and LAA inhibited the PKCe/STAT3/IL-6 signaling pathway and the activation of neurons, astrocytes, and glial cells during inflammatory pain development. IL-6: interleukin-6; LAA: L-2-aminoadipic acid; Mino: minocycline; PKCe: protein kinase C epsilon; STAT3: signal transducer and activator of transcription 3.

In this study, we found that the phosphorylation at Ser727 increased STAT3 interaction with PKCe. This increased IL-6 promoter activity and upregulated IL-6 expression, thus enhancing neuron-glia activation during the development of inflammatory pain. In addition, the PKC $\varepsilon$ inhibitor peptide and STAT3 inhibitor (APTSTAT39R) attenuated FCA-induced nociceptive behavior via IL-6 downregulation (Figure 8).

\section{Conclusions}

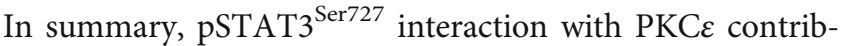
utes to FCA-induced inflammatory pain and IL-6mediated hyperalgesia via IL-6-modulating crosstalk among neurons, astrocytes, and microglia and their activation. The translational value of our findings warrants further investigation.

\section{Abbreviations}

APTSTAT3-9R: STAT3 inhibitor

AUC: $\quad$ Area under the receiver operating characteristic curve
DMEM: $\quad$ Dulbecco's modified Eagle's medium

FCA: $\quad$ Freund's complete adjuvant

GFAP: $\quad$ Glial fibrillary acidic protein

IF: Immunofluorescence

IL-6: Interleukin-6

LAA: $\quad$ L-2-Aminoadipic acid

LPS: $\quad$ Lipopolysaccharide

Mino: $\quad$ Minocycline

PKCe: $\quad$ Protein kinase $C$ epsilon

PWMT: $\quad$ Paw withdraw mechanical threshold

ROC: Receiver operator characteristics curve

STAT3: Signal transducer and activator of transcription 3 .

\section{Data Availability}

The data used to support the findings of this study are available from the corresponding upon request.

\section{Conflicts of Interest}

The authors have no competing interests to declare. 


\section{Authors' Contributions}

$\mathrm{XL}$ and BZ designed and implemented the experiments, curated the data, and wrote and edited the original draft of the manuscript. HY, XY, ZZ, ZP, XL, WJ, and YL collected and statistically analyzed the data. HL, QX, YL, BY, and $\mathrm{HH}$ helped to conduct the study and prepared the experimental materials. XL, DM, and ZL supervised and reviewed the manuscript. All authors read and approved the final version of the manuscript. Xiongjuan Li and Biqiang Zhou contributed equally to this work.

\section{Acknowledgments}

The authors are grateful for the help of colleagues at the Department of Anesthesiology, Shenzhen Second Hospital. This work was supported by the Postdoctoral Science Foundation of China (Xiongjuan Li, 2019M662864, 2019), the Shenzhen Science and Technology Innovation Committee (Zhiheng Liu, GJHZ20180926170402056, 2018), the National Natural Science Foundation of China (Yuqiang Liu, 82001138), and the Science and Technology Planning Project of Shenzhen Municipality (Yuqiang Liu, JCYJ2019 0806164601647, 2019).

\section{References}

[1] L. Sun, Y. Li, X. Jia et al., "Neuroprotection by IFN- $\gamma$ viaastrocyte-secreted IL- 6 in acute neuroinflammation," Oncotarget, vol. 8, no. 25, pp. 40065-40078, 2017.

[2] P. West, B. Viengkhou, I. Campbell, and M. Hofer, "Microglia responses to interleukin- 6 and type I interferons in neuroinflammatory disease," Glia, vol. 67, no. 10, pp. 1821-1841, 2019.

[3] Y. Zhou, Z. Liu, Z. Liu et al., "Interleukin-6: an emerging regulator of pathological pain," Journal of Neuroinflammation, vol. 13, no. 1, p. 141, 2016.

[4] E. Vazquez, J. Kahlenbach, G. Segond von Banchet, C. König, H. Schaible, and A. Ebersberger, "Spinal interleukin-6 is an amplifier of arthritic pain in the rat," Arthritis and Rheumatism, vol. 64, no. 7, pp. 2233-2242, 2012.

[5] C. Kwok, A. Learoyd, J. Canet-Pons, T. Trang, and M. Fitzgerald, "Spinal interleukin- 6 contributes to central sensitisation and persistent pain hypersensitivity in a model of juvenile idiopathic arthritis," Brain, Behavior, and Immunity, vol. 90, pp. 145-154, 2020.

[6] Y. Lin, L. Liu, H. Jiang, J. Zhou, and Y. Tang, "Inhibition of interleukin-6 function attenuates the central sensitization and pain behavior induced by osteoarthritis," European Journal of Pharmacology, vol. 811, pp. 260-267, 2017.

[7] A. Vezzani and B. Viviani, "Neuromodulatory properties of inflammatory cytokines and their impact on neuronal excitability," Neuropharmacology, vol. 96, no. Part A, pp. 70-82, 2015.

[8] M. Nowell, A. Williams, S. Carty et al., "Therapeutic targeting of IL-6TransSignaling counteracts STAT3 control of experimental inflammatory arthritis," Journal of Immunology, vol. 182, no. 1, pp. 613-622, 2009.

[9] E. Shin, D. Dang, Y. Hwang et al., "Significance of protein kinase $\mathrm{C}$ in the neuropsychotoxicity induced by methamphetamine-like psychostimulants," Neurochemistry International, vol. 124, pp. 162-170, 2019.

[10] Y. Gu, G. Li, and L. Huang, "Inflammation induces Epacprotein kinase $\mathrm{C}$ alpha and epsilon signaling in TRPV1mediated hyperalgesia," Pain, vol. 159, no. 11, pp. 2383-2393, 2018.

[11] Z. Hu, T. Zhao, T. Chen, and D. Wang, "Chronic activation of Mas-related gene receptor (Mrg) reduces the potency of morphine-induced analgesia via PKC pathway in naive rats," Brain Research, vol. 1722, article 146363, 2019.

[12] M. Aziz, H. Manoharan, J. Sand, and A. Verma, "Protein kinase $\mathrm{C} \varepsilon$ interacts with Stat 3 and regulates its activation that is essential for the development of skin cancer," Mol Carcinog, vol. 46, no. 8, pp. 646-653, 2007.

[13] K. Taniguchi and M. Karin, "IL-6 and related cytokines as the critical lynchpins between inflammation and cancer," Seminars in Immunology, vol. 26, no. 1, pp. 54-74, 2014.

[14] D. Johnson, R. O'Keefe, and J. Grandis, "Targeting the IL-6/ JAK/STAT3 signalling axis in cancer," Nature Reviews. Clinical Oncology, vol. 15, no. 4, pp. 234-248, 2018.

[15] W. Wang, W. Wang, X. Mei et al., "Crosstalk between spinal astrocytes and neurons in nerve injury-induced neuropathic pain," PLoS One, vol. 4, no. 9, p. e6973, 2009.

[16] J. Qi, C. Chen, Q. Meng, Y. Wu, H. Wu, and T. Zhao, "Crosstalk between activated microglia and neurons in the spinal dorsal horn contributes to stress-induced hyperalgesia," Scientific Reports, vol. 6, no. 1, p. 39442, 2016.

[17] C. Mestre, T. Pelissier, J. Fialip, G. Wilcox, and A. Eschalier, "A method to perform direct transcutaneous intrathecal injection in rats," Journal of Pharmacological and Toxicological Methods, vol. 32, no. 4, pp. 197-200, 1994.

[18] W. Dixon, "Efficient analysis of experimental observations," Annual Review of Pharmacology, vol. 20, no. 1, pp. 441-462, 1980.

[19] Z. Song, B. Xiong, X. Guan et al., "Minocycline attenuates bone cancer pain in rats by inhibiting NF- $\kappa \mathrm{B}$ in spinal astrocytes," Acta Pharmacologica Sinica, vol. 37, no. 6, pp. 753-762, 2016.

[20] Y. Zhou, D. Liu, S. Chen et al., "Minocycline as a promising therapeutic strategy for chronic pain," Pharmacological Research, vol. 134, pp. 305-310, 2018.

[21] A. Saleem, M. Saleem, M. Akhtar, M. Shahzad, and S. Jahan, "Polystichum braunii extracts inhibit complete Freund's adjuvant-induced arthritis via upregulation of I- $\kappa \mathrm{B}, \mathrm{IL}-4$, and IL-10, downregulation of COX-2, PGE ${ }_{2}$, IL- $1 \beta$, IL- $6, \mathrm{NF}-\kappa \mathrm{B}$, and TNF- $\alpha$, and subsiding oxidative stress," Inflammopharmacology, vol. 28, no. 6, pp. 1633-1648, 2020.

[22] W. Ma and R. Quirion, "Targeting invading macrophagederived PGE2, IL-6 and calcitonin gene-related peptide in injured nerve to treat neuropathic pain," Expert Opinion on Therapeutic Targets, vol. 10, no. 4, pp. 533-546, 2006.

[23] W. Sun and C. Chen, "Roles of proton-sensing receptors in the transition from acute to chronic pain," Journal of Dental Research, vol. 95, no. 2, pp. 135-142, 2016.

[24] M. Hossain, S. Unno, H. Ando, Y. Masuda, and J. Kitagawa, "Neuron-glia crosstalk and neuropathic pain: involvement in the modulation of motor activity in the orofacial region," International Journal of Molecular Sciences, vol. 18, no. 10, p. 2051, 2017.

[25] H. Zhao, A. Alam, Q. Chen et al., "The role of microglia in the pathobiology of neuropathic pain development: what do we 
know?," British Journal of Anaesthesia, vol. 118, no. 4, pp. 504516, 2017.

[26] S. Merighi, S. Bencivenni, F. Vincenzi, K. Varani, P. A. Borea, and S. Gessi, " $\mathrm{A}_{2 \mathrm{~B}}$ adenosine receptors stimulate IL-6 production in primary murine microglia through p38 MAPK kinase pathway," Pharmacological Research, vol. 117, pp. 9-19, 2017.

[27] E. Toton, N. Lisiak, B. Rubis et al., "The tetramethoxyflavone zapotin selectively activates protein kinase $\mathrm{C}$ epsilon, leading to its down-modulation accompanied by Bcl-2, c-Jun and cFos decrease," European Journal of Pharmacology, vol. 682, no. 1-3, pp. 21-28, 2012.

[28] S. Gessi, P. A. Borea, S. Bencivenni, D. Fazzi, K. Varani, and S. Merighi, "The activation of $\mu$-opioid receptor potentiates LPS-induced NF-kB promoting an inflammatory phenotype in microglia," FEBS Letters, vol. 590, no. 17, pp. 2813-2826, 2016.

[29] J. Herrmann, T. Imura, B. Song et al., "STAT3 is a critical regulator of astrogliosis and scar formation after spinal cord injury," The Journal of Neuroscience, vol. 28, no. 28, pp. 7231-7243, 2008.

[30] H. Arima, M. Hanada, T. Hayasaka et al., "Blockade of IL-6 signaling by MR16-1 inhibits reduction of docosahexaenoic acid-containing phosphatidylcholine levels in a mouse model of spinal cord injury," Neuroscience, vol. 269, pp. 1-10, 2014.

[31] J. Kang, Y. Park, D. Lee et al., "Intracellular Interaction of Interleukin (IL)-32 $\alpha$ with Protein Kinase $\mathrm{C} \epsilon$ (PKC $\epsilon$ ) and STAT3 Protein Augments IL-6 Production in THP-1 Promonocytic Cells," The Journal of Biological Chemistry, vol. 287, no. 42, pp. 35556-35564, 2012.

[32] Y. Aikawa, K. Morimoto, T. Yamamoto et al., "Treatment of arthritis with a selective inhibitor of c-Fos/activator protein1," Nature Biotechnology, vol. 26, no. 7, pp. 817-823, 2008.

[33] H. Motomura, S. Seki, S. Shiozawa, Y. Aikawa, M. Nogami, and T. Kimura, "A selective c-Fos/AP-1 inhibitor prevents cartilage destruction and subsequent osteophyte formation," Biochemical and Biophysical Research Communications, vol. 497, no. 2, pp. 756-761, 2018.

[34] H. Wang, H. Zhan, X. Jiang et al., "A novel miRNA restores the chemosensitivity of AML cells through targeting FosB," Frontiers in Medicine, vol. 7, article 582923, 2020.

[35] H. Wang, K. Ji, L. Zhang et al., "Inhibition of c-Fos expression attenuates IgE-mediated mast cell activation and allergic inflammation by counteracting an inhibitory AP1/Egr1/IL-4 axis," Journal of Translational Medicine, vol. 19, no. 1, p. 261, 2021.

[36] Q. Zhao, K. Zhang, Y. Li et al., "OLFML2A is necessary for anti-triple negative breast cancer effect of selective activator protein-1 inhibitor T-5224," Translational Oncology, vol. 14, no. 8, article 101100, 2021.

[37] S. Cankaya, B. Cankaya, U. Kilic, E. Kilic, and B. Yulug, "The therapeutic role of minocycline in Parkinson's disease," Drugs Context, vol. 8, article 212553, 2019.

[38] D. Romero-Miguel, N. Lamanna-Rama, M. Casquero-Veiga, V. Gómez-Rangel, M. Desco, and M. Soto-Montenegro, "Minocycline in neurodegenerative and psychiatric diseases: an update," European Journal of Neurology, vol. 28, no. 3, pp. 1056-1081, 2021.

[39] Y. Naderi, Y. Panahi, G. Barreto, and A. Sahebkar, "Neuroprotective effects of minocycline on focal cerebral ischemia injury: a systematic review," Neural Regeneration Research, vol. 15, no. 5 , pp. $773-782,2020$.
[40] C. Smith, H. Sayles, T. Mikuls, and K. Michaud, "Minocycline and doxycycline therapy in community patients with rheumatoid arthritis: prescribing patterns, patient-level determinants of use, and patient-reported side effects," Arthritis Research \& Therapy, vol. 13, no. 5, p. R168, 2011.

[41] W. Li, T. Guo, X. Shi et al., "Substance P spinal signaling induces glial activation and nociceptive sensitization after fracture," Neuroscience, vol. 310, pp. 73-90, 2015.

[42] T. Sato, Y. Ito, and T. Nagasawa, "Regulatory effects of the Llysine metabolites, L-2-aminoadipic acid and L-pipecolic acid, on protein turnover in C2C12 myotubes," Bioscience, Biotechnology, and Biochemistry, vol. 80, no. 11, pp. 2168-2175, 2016.

[43] H. Li, B. Bui, G. Cull, F. Wang, and L. Wang, "Glial cell contribution to basal vessel diameter and pressure-initiated vascular responses in rat retina," Investigative Ophthalmology \& Visual Science, vol. 58, no. 1, pp. 1-8, 2017.

[44] S. Baudoux and D. Parker, "Glial-toxin-mediated disruption of spinal cord locomotor network function and its modulation by 5-HT," Neuroscience, vol. 153, no. 4, pp. 1332-1343, 2008.

[45] A. L. Hung, M. Lim, and T. Doshi, "Targeting cytokines for treatment of neuropathic pain," Scandinavian Journal of Pain, vol. 17, no. 1, pp. 287-293, 2017.

[46] E. Favalli, "Understanding the role of interleukin-6 (IL-6) in the joint and beyond: a comprehensive review of IL- 6 inhibition for the management of rheumatoid arthritis," Rheumatology and Therapy, vol. 7, no. 3, pp. 473-516, 2020.

[47] S. Kang, T. Tanaka, M. Narazaki, and T. Kishimoto, "Targeting interleukin-6 signaling in clinic," Immunity, vol. 50, no. 4, pp. 1007-1023, 2019. 